\title{
A Systematic Literature Review on the Automatic Creation of Tactile Graphics for the Blind and Visually Impaired
}

\author{
Mukhriddin Mukhiddinov ${ }^{1} \mathbb{D}$ and Soon-Young Kim $^{2, *}$ \\ 1 Department of Computer Engineering, Gachon University, Sujeong-gu, Seongnam-si 13120, Korea; \\ mukhiddinov18@gachon.ac.kr \\ 2 Department of Physical Education, College of Arts and Physical Education, Gachon University, \\ Sujeong-gu, Seongnam-si 13120, Korea \\ * Correspondence: klpga0166@gachon.ac.kr
}

Citation: Mukhiddinov, M.; Kim, S.-Y. A Systematic Literature Review on the Automatic Creation of Tactile Graphics for the Blind and Visually Impaired. Processes 2021, 9, 1726. https://doi.org/10.3390/pr9101726

Academic Editor: Faisal Jamil

Received: 2 September 2021

Accepted: 22 September 2021

Published: 26 September 2021

Publisher's Note: MDPI stays neutral with regard to jurisdictional claims in published maps and institutional affiliations.

Copyright: (c) 2021 by the authors. Licensee MDPI, Basel, Switzerland. This article is an open access article distributed under the terms and conditions of the Creative Commons Attribution (CC BY) license (https:// creativecommons.org/licenses/by/ $4.0 /)$.

\begin{abstract}
Currently, a large amount of information is presented graphically. However, visually impaired individuals do not have access to visual information. Instead, they depend on tactile illustrations-raised lines, textures, and elevated graphics that are felt through touch-to perceive geometric and various other objects in textbooks. Tactile graphics are considered an important factor for students in the science, technology, engineering, and mathematics fields seeking a quality education because teaching materials in these fields are frequently conveyed with diagrams and geometric figures. In this paper, we conducted a systematic literature review to identify the current state of research in the field of automatic tactile graphics generation. Over 250 original research papers were screened and the most appropriate studies on automatic tactile graphic generation over the last six years were classified. The reviewed studies explained numerous current solutions in static and dynamic tactile graphics generation using conventional computer vision and artificial intelligence algorithms, such as refreshable tactile displays for education and machine learning models for tactile graphics classification. However, the price of refreshable tactile displays is still prohibitively expensive for low- and middle-income users, and the lack of training datasets for the machine learning model remains a problem.
\end{abstract}

Keywords: tactile graphics generation; refreshable tactile displays; artificial intelligence; machine learning; visually impaired; computer vision; haptic devices

\section{Introduction}

The sense of touch is an indispensable source of data for individuals investigating scenes in nearby areas. It passes various tactile data, such as pressing factor, torment, temperature, and vibration, to the focal sensory system, thereby helping people to perceive their environments and avoid potential wounds [1]. According to previous studies, the sensory system associated with the feeling of touch is superior to the visual and auditory systems in perceiving accurate and complete characteristics of objects [1]. As the 21st century has ushered in the information age, the amount of data available for downloading, archiving, searching, and browsing is nearly limitless. One of the main reasons for this phenomenon is the widespread use of the Internet by the public as people seek to learn more about their surroundings and the world in which they live. For visually impaired people, tactile forms of graphics are an essential means of studying and understanding the world. However, tactile graphics with raised lines designed with common materials, such as paper, are static. While accessible and refreshable braille displays can change content dynamically, they are excessively costly for some blind communities, and their dimensions and size are limited. These shortcomings prevent the widespread use of tactile graphics and limit the display of large graphics or datasets.

The main purpose of this study was to provide an objective review of the current state of research on automated tactile graphic generation and the proposed solutions. The review 
of scientific articles is important as they indicate and facilitate the improvement of the current state of research, in addition to providing best practices for learning and providing new ideas [2]. Our review concentrated on research on the performance of different static and dynamic tactile graphic generation methods using conventional computer vision and machine learning approaches. Another focus of study was to automate or semiautomate the generation of tactile graphics or other convenient formats. To the best of our knowledge, there has not been sufficient comprehensive analytical survey of studies on these novel touch-based technologies for producing graphics accessible to people with visual disabilities [3]. However, as this study showed, several articles focused on automatic tactile graphics generation, especially static tactile graphics generation. The analyzed studies enabled us to give a clear summary of the capability of automatic tactile graphics production, particularly issues that have been effectively addressed and the remaining difficulties.

\section{Background and Motivation}

\subsection{Background of Tactile Graphics and Automatic Tactile Graphics Generation}

Today, graphical representations of many types of information are expanding. Infographics are frequently used in our daily lives, for instance, to present climate reports in newspapers, statistical information, place layouts, public transportation graphs, and other general purposes [4]. Graphics are used to demonstrate information instantly and simply by presenting data in a compact and organized manner. Humans usually perceive graphics using a vision system, which is a common natural approach for understanding them. However, people with visual disabilities who perceive the environment through the sense of touch are unable to understand graphical representations, limiting their ability to fully benefit from the information age. This community comprises blind and visually impaired (BVI) individuals. According to the World Health Organization, at least 2.2 billion people worldwide have vision impairment or blindness, with at least one billion having a vision impairment that could have been avoided or is still unaddressed. Tens of millions of people have severe vision impairment and could benefit from rehabilitation that is currently unavailable to them [5]. The skill to learn and understand graphical illustrations is particularly necessary for individuals who study or work in areas such as engineering, technology, economics, mathematics, and science. Therefore, it is fundamental to acquire this skill at a young age. However, learners with visual impairments do not have access to visual information. Hence, the principal issue is how to create graphics for visually impaired people at an early grade in school [6]. There are two considerations in addressing the issue: (1) the prospect of learners with visual disabilities who must learn how to understand and read tactile graphics, (2) the prospect of educators who must provide this information. A fundamental requirement for making tactile graphics available for learners with visual disabilities is a methodology that is simple and natural for both learners and educators to utilize.

The most common answer for making tactile graphics available is to provide an alternative text that contains a description of the graphics. In some situations, such descriptions are the only opportunity to create complex tactile graphics. Although various methods have been used to automatically produce alternative text for complex graphics [7], they are not currently possible for lecture materials. Presently, the descriptions are manually generated by specialists. Tactile graphics, which are pictures with a raised surface that can be touched with the fingertips or part of the hand, are another option for producing graphics. Examples of tactile representations are diagrams, charts, graphs, maps, images, and other nontextual spatial forms. Tactile graphics can be used for diverse goals, such as education, entertainment, navigation, and professional activities. The creation process ranges from thermoforming and swell paper to embossing on a thicker paper. In recent years, special printers such as Index Braille Everest-D, PIAF, ViewPlus Tiger, and IRIE Embossers have been utilized to print tactile graphics from digital images. According to Zebehazy \& Wilton [6], the presentation of textual information along with tactile graphics 
is the most suitable form of presenting information to BVI students in school. In the study, the authors demonstrated the significance of tactile graphics in the learning results of students with low vision and BVI students. The ability to independently study tactile graphics, find information, and respond to information-related questions is considered an essential component of the learning process [6]. Pictures and diagrams are increasingly being utilized as individual means of providing information, as approximately $70 \%$ of textbooks provide information using only diagrams without text descriptions [8]. To translate, understand, and use these visual images as tactile graphics, BVI students need sighted partners. Moreover, the diagram conversion process is quite expensive and can take hours to complete, assuming that a professional is available.

The ability to effectively learn and understand tactile graphics and diagrams is an essential requirement of the education of visually impaired students, although it is an ability that requires guidance and practice. Numerous educators have observed that BVI students have some inconveniences in exploring tactile graphics without personal guidance. Pictures are an essential element of science, technology, engineering, and mathematics (STEM) training, but they are frequently inaccessible to BVI students. One of the main obstacles to the success of BVI students in STEM areas is lack of access to diagrams and charts in the training materials. Additionally, they may struggle to explain detailed distinctions between line styles or textures and need to handle the narrow and complicated arrangements of lines and braille. Problems with these formats limit BVI students from individually accessing educational content on tactical graphics because they require further explanation from sighted partners. In many cases, diagrams and figures in books are not in tactile graphics or other accessible formats. To address this issue, in some cases, specific diagrams and figures are explained orally by educators. In other cases, tactile graphics are created by selecting pictures from teaching material in which the text has previously been converted into braille format; however, this is a costlier alternative. For instance, in a questionnaire of academically performing 9-19-year-old BVI students in the United States and Canada, $45 \%$ reported encountering three or more tactile graphics per week, $25 \%$ reported encountering one or two tactile graphics per week, $24 \%$ reported encountering tactile graphics only a few times per month, and $6 \%$ reported never using tactile graphics in school [9]. Despite this observation, the incorporation of as much as $93.3 \%$ of print graphics in a tactile form in the braille transcriptions of secondary (9-12th grade) science and math textbooks (6.7\% of graphics were found to be omitted in the Braille transcriptions) [10], and attitudes from the surveyed BVI students that tactile graphics are necessary, especially in STEM $[9,11]$.

While tactile graphics can be created manually by experts, the method is timeconsuming. According to the self-reports of some experts, it can take from one hour to several hours to prepare and complete one tactile graphic. Although this process has been slightly reduced with graphic manipulation programs (e.g., Adobe Photoshop or Gimp, combined with instructions and texture kits [12]) that run on a regular computer, the time required to complete the graphics is still considerable. Hence, fewer tactile graphics are accessible to touch-based readers, and unless the images are used repeatedly, such as in class, by different users over time, they are usually not accessible instantly upon request. Institutional sectors that require many charts, diagrams, and graphics, such as STEM, are frequently underserved owing to the lack of technical facilities. Furthermore, because these graphs require significant funding, many BVI students living below the poverty line cannot use them.

Automatic tactile graphic generation applications can significantly reduce the processing and development time of tactile graphics while increasing their accessibility to BVI individuals of all ages. Furthermore, they can be used as a starting point for additional diagrammatic changes if an instructor desires to have control over the resulting graphics. Although various solutions have been implemented by some researchers and private companies, not all the solutions facilitate learning. For instance, QuickTac, TactileView, and Firebird Graphics Editor are commercially available softwares for assisting teachers 
of BVI students to produce computer-generated tactile graphics. However, they all have limitations regarding functionality and adaptability, thus preventing their widespread use. Way et al. [13], one of the pioneers of automatic tactile graphics generation, investigated the use of image processing algorithms available between 1997 and 2007 for automatic tactile graphics generation. However, stronger modern algorithms combined with image simplification and perspective correction were required, as well as user experiments and observations with professional approaches [13-17]. Ladner et al. [18] studied the transformation of geometrical graphs to tactile graphics; however, they did not consider diagrams and natural images.

Although the advantages of tactile graphics have been adequately documented, there are a few drawbacks. One of the drawbacks is their limited capacity to hold information [19]. It is challenging to combine information, such as titles or explanations, without creating an overly complex tactile graphic [20]. Consider, for instance, a tactile map that includes crossings, streets, and numerous landmarks. It would be impractical to add a tactile label to each map characteristic. To solve this problem, researchers have been investigating alternative techniques to supplement tactile graphics with additional data. Sound [21,22] and haptics [23] are two of the most promising methods. Sound has been implemented to explain the content of tactile graphics to provide text-to-speech information based on object and text recognition [11], QR code [21], or haptic information [22]. Meanwhile, haptic-tactile graphs $[24,25]$ can produce force-feedback based on user contact. Compared with conventional tactile graphics, these interactive tactile graphics could increase the effectiveness of examining content and facilitate learning $[19,20]$. Meanwhile, these methods do have their weaknesses: they restrict the skills of the BVI student (1) to acquire instant surveys of spatial knowledge with two-handed interaction [26] and (2) to compare various pieces of the graphic spatially by utilizing the hands as a connecting point [27].

Another drawback of tactile graphics is their static content and high cost. In the last decade, some researchers proposed several methods for automating tactile graphic design [16,28,29]; however, changing static tactile graphics after creation requires some effort. Refreshable braille displays have been developed as a solution to this shortcoming. Dynamic tactile graphics can change their content in response to the interaction of BVI users. Jungil et al. [30] proposed an education assistive technology (AT) system based on a graphic-haptic electronic board. The system facilitated the automatic conversion of images to refreshable braille displays, enabling the authoring and real-time distribution of education materials to BVI students. Kim et al. [31] proposed a 2D multi-array refreshable braille display utilizing an electronic book translator software because of its accuracy and high speed. The procedure was versatile and applied a 2D multi-array refreshable braille display to represent media content and shapes. HyperBraille [32] is a current refreshable braille display with one of the largest touch-sensitive pin-matrix displays on the market (7200 pins arranged in 120 columns and 60 rows). Researchers have shown some interactive systems that apply commercially available refreshable displays to produce a dynamic tactile map with geographic commentary [33,34]. However, the price of a refreshable tactile display, such as HyperBraille, is expensive, ranging from 2000 USD for an 18-character display to 50,000 USD for a half-page of braille. Refreshable braille displays use several actuator technologies, such as piezoelectric actuators, electromagnetic actuators, electroactive polymers, shape memory alloys, and hydraulic and pneumatic actuation.

\subsection{Artificial Intelligence Algorithms for Generating Tactile Graphics}

The process of all of the aforementioned methods entails the translation of visual information into tactile graphics using conventional computer vision algorithms and the regular intervention of a sighted person; hence, the methods influence the independence of BVI individuals [35]. Meanwhile, the final tactile graphics should preferably be examined by a teacher of BVI students to define their quality. This is because the teacher has obtained specific training and certifications to satisfy the educational requirements of BVI students. However, owing to geographical, social, or economic circumstances, this role may be 
performed by friends, parents, or teachers without sufficient training and experience in generating tactile graphics. Recent research advances have been made to produce an application capable of automatic translation. Nevertheless, the main limitation of these methods is that the quality of the final tactile graphics is not verified before receiving feedback from a BVI student or tactile graphics maker. In recent years, the use of artificial intelligence (AI) technologies to overcome such limitations has been promoted by many researchers. For example, Gonzalez et al. [36] introduced a method for assessing the level of complexity of images and then converting images that are understandable into tactile graphics using a machine learning model. They also proposed a method for evaluating the score results using a simple qualitative scale with three values: good images $>80 \%$, fair images $30-79 \%$, and bad images $<30 \%$. Good images can easily be transformed into tactile graphics. Although fair images may be used, the model cannot ensure good tactile graphics with the given image. Meanwhile, bad images are too complex to be transformed into acceptable tactile graphics. Researchers have also developed a touchscreen tablet with audio feedback [37], an accessibility system for web documents [38], a tactile graphics finder [35], video description [39,40], bas-reliefs [41], and touchscreen interactions for environmental perception [42] using AI technologies to make visual information easy to explain to BVI individuals.

The main contributions of the current study to the field of automatic tactile graphics generation were as follows:

- It has become the first systematic review paper in the field of static and dynamic tactile graphic generation using conventional computer vision and AI technologies. It provided an in-depth analysis of articles from the last six years and explained the current state of this research field.

- It compared different tactile graphics generation approaches for BVI individuals and summarized the results of the studies.

- It determined the level of importance of tactile graphics in the education and social life of BVI individuals.

- It defined the role of $\mathrm{AI}$ in automatic tactile graphics generation.

\subsection{Existing Literature Review and Motivation}

We conducted a search in the archives of selected electronic databases, journals, and open-access publishers to find literature reviews on automatic tactile graphics generation over the last decade based on various keywords. The terms "literature survey" and "systematic literature reviews" were used to search on 12 electronic databases and five open-access publishers, and journals in the fields of information technology and computer science were selected. Through this methodology, we identified 30 literature reviews in the fields of information technology and informatics. Most of the reviews were basic nonsystematic reviews and classic literature reviews.

Nevertheless, based on an in-depth analysis, we distinguished six systematic literature reviews related to automatic tactile map generation [4], quantitative empirical evaluations of technology designed for BVI individuals [2], touch-based accessible graphics [3], mathematics education for BVI students [43], image accessibility for screen-reader users [44], and tactile cartography in the digital age [45]. To the best of our knowledge, these systematic literature reviews are some of the latest in this field, indicating that the literature on tactile graphics has not been sufficiently analyzed. AI technologies for BVI individuals were not studied. Additionally, the available literature was unable to answer the general questions that motivated the present study, which follow:

- What are the most advanced accomplishments and innovations in tactile graphics generation?

- What is the impact of AI on automatic tactile graphics generation for BVI individuals?

- What is the difference between scientific results and commercially available technologies in the life of BVI individuals?

- What are the main gaps and difficulties that are not addressed in research today? 
A systematic literature review was conducted in various research areas by the authors for a comprehensive study of the research direction, giving the results of recent achievements in the research field as well as shortcomings, and recommendations for the future development of this field. A systematic literature review fairly synthesizes existing achievements; the review should be done by a predefined search procedure, which secures the absoluteness of the search [46]. It is a summary of fundamental research that includes a precise description of the goals, techniques, and knowledge, and it is conducted using an exact and reproducible methodology.

The remainder of the paper is organized as follows: In Section 3, the review methodology is clarified and research questions are identified. In Section 4, the results of the analysis and answers to the questions are presented. In Section 5, some limitations and issues of existing solutions in the field of tactile graphics generation are highlighted and the solutions are discussed. Finally, the summary of our findings is presented in Section 6.

\section{Review Methodology}

We conducted a systematic review of tactile graphics generation using conventional computer vision and AI algorithms. Additionally, we assessed the quality of the literature and discussed potential representations of the results and future directions. The study followed comprehensive systematic literature review guidelines for software engineering [46].

\subsection{Research Questions}

We also defined specific research questions (RQs) in this study to answer the general questions mentioned earlier. Based on the RQs, we searched for and selected the primary literature over the last six years. The principal focus was to analyze the role of tactile graphics in the education of BVI individuals and their adaptation to the society (RQ1). We then identified the link between the current methods and commercially available technologies (RQ2). Furthermore, we highlighted the advantages of solutions using AI and the gaps that need to be addressed for future developments (RQ3). Thus, the following key questions were defined:

- $\quad$ RQ1: What is the role of tactile graphics in the education of BVI individuals and their adaptation to the society?

- RQ2: What are the current methods and commercially available technologies for dynamic tactile graphics generation?

- RQ3: What are the advantages of solutions using AI and 3D printers and what are the gaps that need to be addressed for future developments?

These research questions were formulated not only to help analyze and compare the scientific results but also to determine the current state and future directions of this field. Inclusion and exclusion criteria were used to determine whether the initial articles qualified for the systematic literature review.

\subsection{Search Strategy}

To identify relevant published studies and reduce search bias, we searched several electronic databases and digital libraries, including IEEE Xplore, ACM Digital Library, and Web of Science multiple times (Table 1). We also considered the most suitable open-access publishers, using keywords from each category such as "target user", "target Object", "supported feature, and "supported devices" to reduce search bias (Tables 1 and 2). The category of target user included "deaf-blind", "visual impairment", "blind", "vision loss", "visual disability", and "low vision". The category of target object included "tactile graphics", "natural scene image", "picture", "painting and drawing", and "diagram and map". The category of supported feature consisted of "touch sense", "feedback", "braille cell and pin", and "haptic". The category of supported device included "refreshable tactile display", "braille displays", "tablet", "touch screen", and "tangible screen". We included studies published between 1 January 2015 and 1 March 2021 (Figure 1) because there was 
an increase in AT for BVI individuals and a transition from conventional algorithms to AI algorithms during this period.

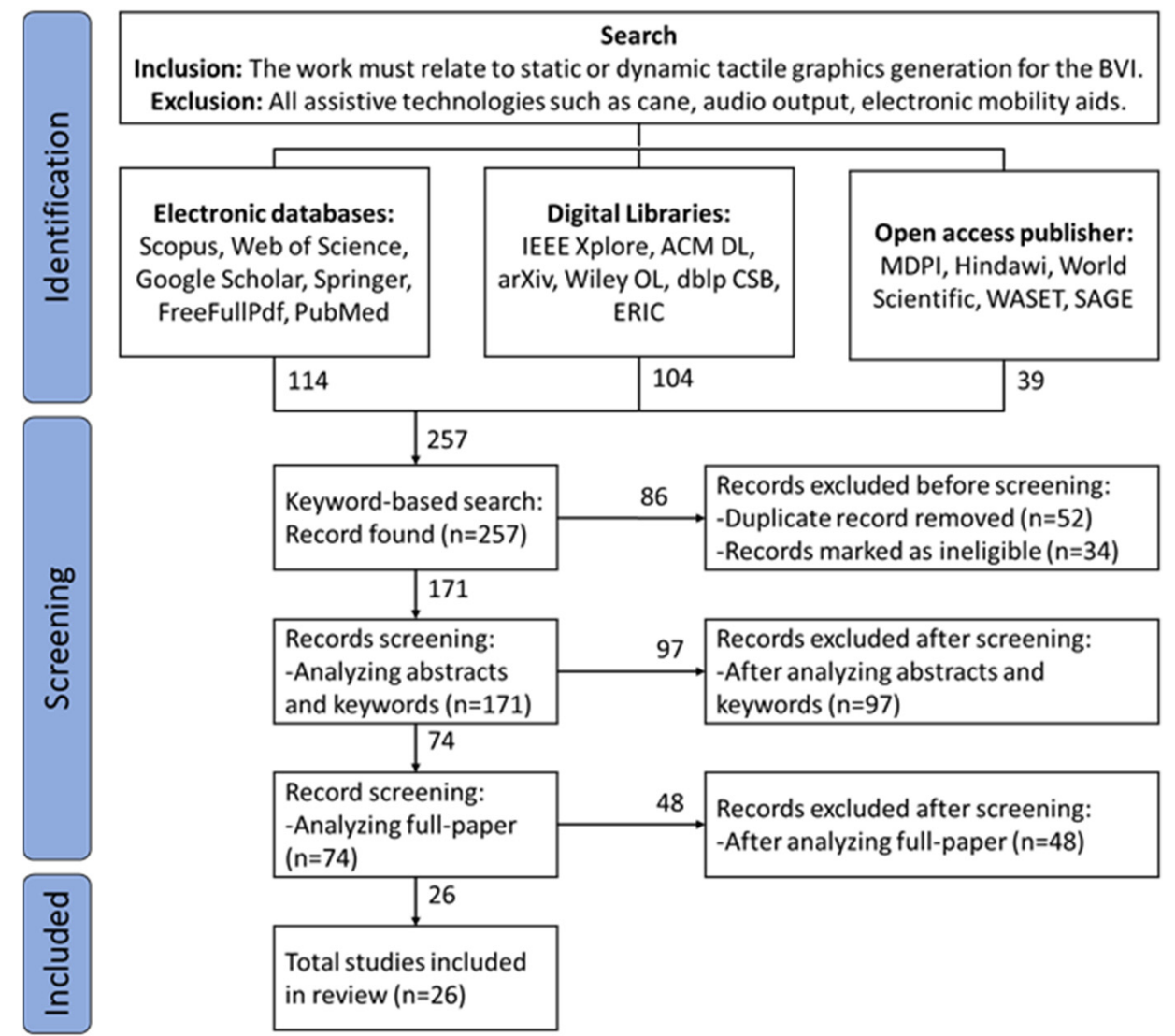

Figure 1. The flow diagram for the review process with the number of included and excluded articles in each step. A PRISMA flow diagram [47].

Table 1. Electronic databases and digital libraries used during the review process.

\begin{tabular}{|c|c|c|c|}
\hline Source & URL & Date of Search & Results \\
\hline IEEE Xplore & https://ieeexplore.ieee.org/ & 1 March 2021 & 45 \\
\hline ACM DL & https://dl.acm.org/ & 1 March 2021 & 36 \\
\hline Web of Science & http:/ /webofknowledge.com/ & 2 March 2021 & 18 \\
\hline Scopus & https://www.scopus.com/ & 2 March 2021 & 23 \\
\hline Google Scholar & https:/ / scholar.google.com/ & 3 March 2021 & 56 \\
\hline Springer & https:/ /link.springer.com/ & 3 March 2021 & 8 \\
\hline FreeFullPDf & http:/ / www.freefullpdf.com/ & 3 March 2021 & 6 \\
\hline arXiv & https://arxiv.org/ & 4 March 2021 & 5 \\
\hline Wiley OL & https:/ /onlinelibrary.wiley.com/ & 4 March 2021 & 4 \\
\hline dblp CSB & https://dblp.uni-trier.de/ & 4 March 2021 & 7 \\
\hline PubMed & https://pubmed.ncbi.nlm.nih.gov/ & 4 March 2021 & 3 \\
\hline ERIC & https://eric.ed.gov/ & 4 March 2021 & 7 \\
\hline
\end{tabular}


Table 2. Open access publishers used during the review process.

\begin{tabular}{ccccc}
\hline Source & URL & Date of Search & Results \\
\hline MDPI & https://www.mdpi.com/ & 2 March 2021 & 5 \\
\hline Hindawi & https://www.hindawi.com/ & 3 March 2021 & 11 \\
\hline World Scientific & https://www.worldscientific.com/ & 4 March 2021 & 4 \\
\hline WASET & https://publications.waset.org/ & 4 March 2021 & 5 \\
\hline SAGE & https://journals.sagepub.com/ & 4 March 2021 & 14 \\
\hline
\end{tabular}

\subsection{Criteria for Inclusion and Exclusion}

Afterward, we developed inclusion and exclusion criteria to evaluate the quality of articles found in these electronic databases for the initial corpus.

The most notable inclusion criteria were:

- The work must have related to tactile graphics generation for BVI individuals. Static or dynamic tactile graphics generation were also considered.

- Works related to tactile drawing by sighted persons were considered but their results were examined in depth.

- All methods based on AI algorithms for BVI individuals were analyzed in-depth and the results were sorted according to their novelty.

The most notable exclusion criteria were:

- Works related to tactile sensors for robotics were not considered.

- All AT, including cane, audio output, and electronic mobility aids, were not considered.

- Works that focus only on braille text were not considered.

\subsection{Electronic Databases and Digital Libraries}

As a result, 257 studies were identified for the primary corpus (Tables 1 and 2). All the collected articles were saved and managed using Mendeley reference management software. First, article duplications were checked and repeated articles were removed. The titles and abstracts of the articles were then analyzed and separated using tags.

Subsequently, we focused on articles from reputable sources describing tactile graphics generation: ACM Conference on Human Factors in Computing Systems (CHI), ACM SIGACCESS Conference on Computers and Accessibility (ASSETS), ACM Transactions on Accessible Computing (TACCESS), ACM Transactions on Computer-Human Interaction, ACM Symposium on User Interface Software and Technology, ACM International Conference on PErvasive Technologies Related to Assistive Environments, ACM International Conference on Tangible, Embedded, and Embodied Interaction, and International Conference on Computers Helping People with Special Needs (ICCHP). We also focused on the main journals in this field, such as the British Journal of Visual Impairment, Journal of Blindness Innovation and Research, and Journal of Visual Impairment and Blindness.

\subsection{Study Selection}

First, we reviewed the 257 studies in the initial corpus and selected articles that were not duplicates and published in the last six years. At this stage, 86 studies were excluded because 52 were duplicates and 34 were incompatible with the purpose of this review. In the next step, we evaluated the quality of each study and analyzed the title, abstract, and keywords. Any inappropriate decisions reported by researchers are discussed together. As a result, 97 studies that did not match the quality evaluation were excluded from the study. The same evaluation process was applied to the analysis of the full papers, and 48 papers that were ineligible for the scope of this study were excluded from the literature review. After performing the inclusion, exclusion and quality assessment processes, 26 primary studies met the purpose of this review (Figure 1). 


\section{Review Results}

As a result of the systematic review, 26 studies qualified for further analysis. The papers were primarily summarized with regard to the three research questions defined in Section 3.

\subsection{Overview}

It should be noted that there has been an increasing interest among researchers in developing tactile graphics and AT for BVI individuals every year, as evidenced by the publication of more articles. A review of the publication year of all the identified studies showed this increase (Figure 2). The 2021 publications were not routinely searched; hence, only 16 articles (until 1 March 2021) were reviewed. To the best of our knowledge, 79 papers were published in this field in 2020, which was the highest number of publications in any year. Mendeley reference management software was used to save and manage all 257 articles. Moreover, the years of publication, titles, and abstracts were analyzed, and appropriate classifications were made. Affiliates of the authors of published articles were also noted, and it was found that researchers in 27 countries had researched this area, as shown in Figure 3. In terms of authors' affiliation, the United States had the most papers, with 52. It was followed by Germany (19), France (18), Japan (18), India (16), and Italy (15).

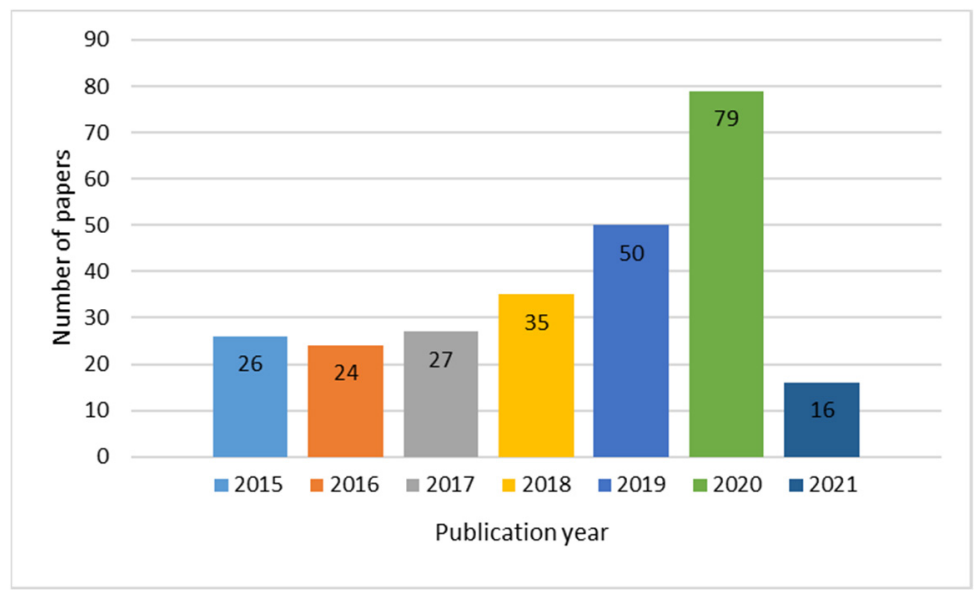

Figure 2. Number of papers analyzed in the abstract and keywords stage.

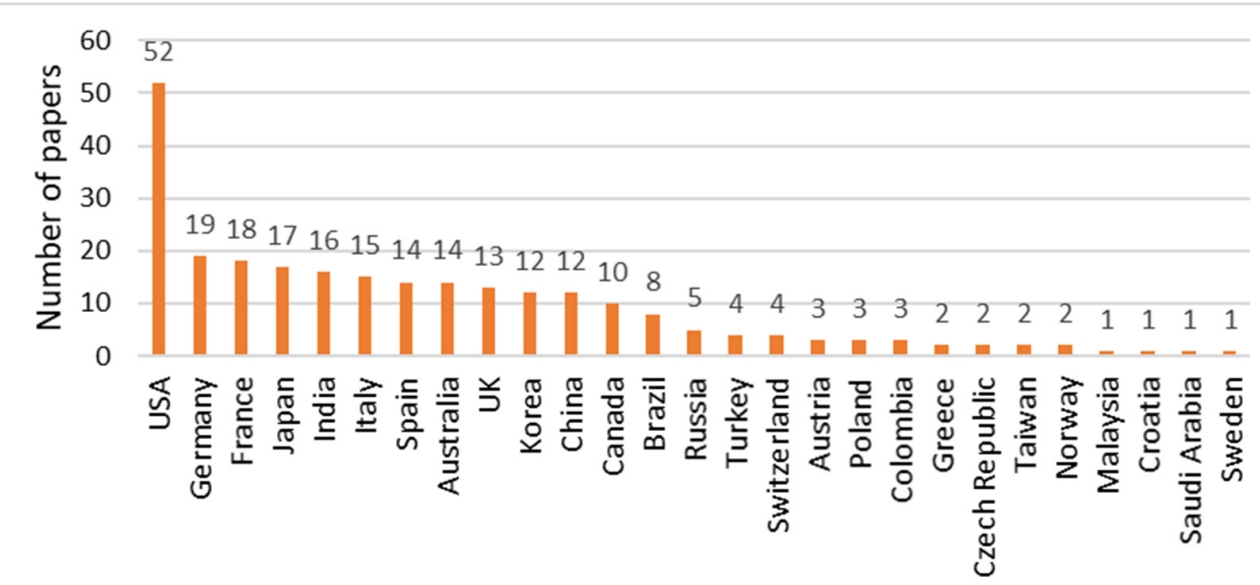

Name of Countries

Figure 3. Number of papers published in the country of authors' affiliation. 


\subsection{Title and Abstract Analysis}

In the title and abstract analyses, tags were utilized to identify the types of articles and technology used. We divided all the articles into 12 types of technologies related to tactile graphics generation. Abstract and keywords analyses of all the 171 articles showed that more work was done in three major technology research areas: tactile graphics ( 36 articles, $21.05 \%$ ), 3D tactile graphics (29 articles, $17 \%$ ), and audio with tactile graphics ( 23 articles, 13\%) (Figure 3). In contrast, tactile graphics editing and tactile overlay technologies have not been sufficiently explored, with each having six (4\%) and seven articles (4\%), respectively. Accordingly, we have listed the number of articles and the corresponding percentages in other technology research in Figure 4.

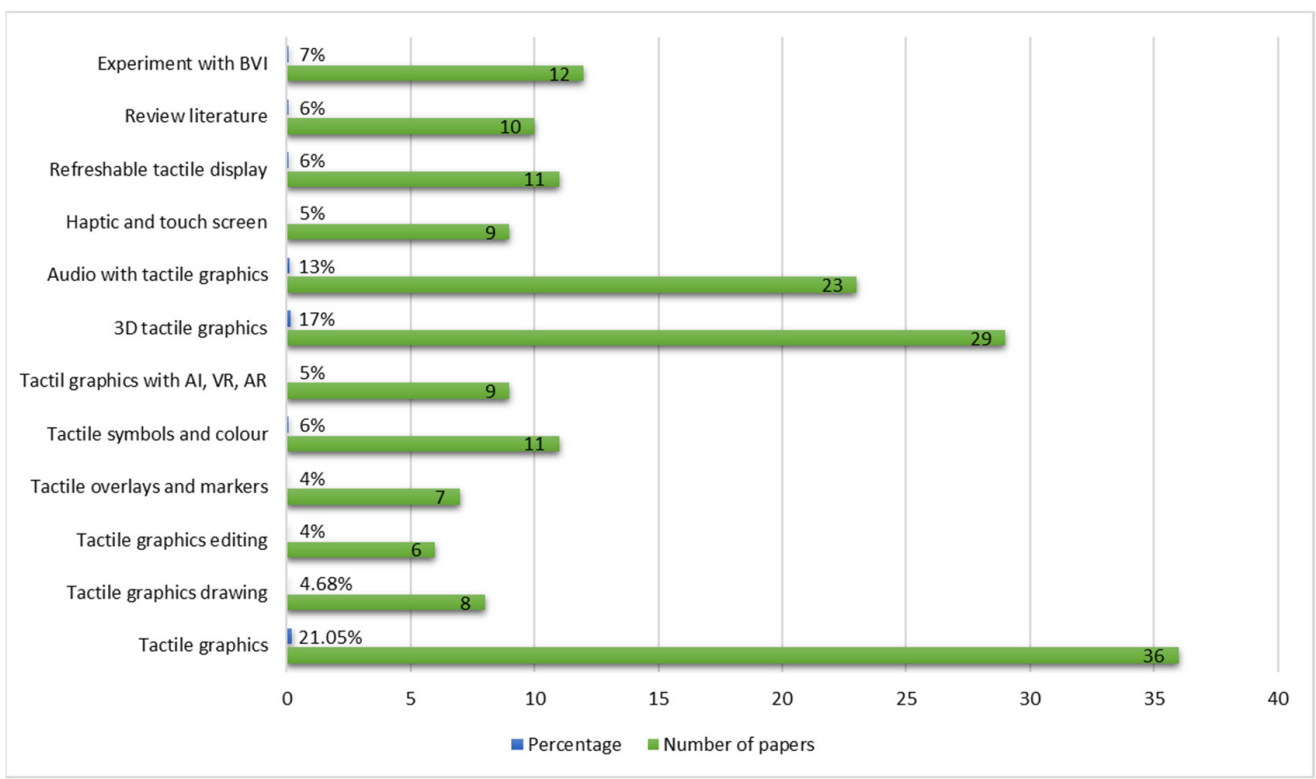

Figure 4. Technology research related to the tactile graphics field in the abstracts and keywords analyses stage.

\subsection{Full-Paper Analysis}

In the second step of the analysis process, called full-paper screening, 26 primary articles were selected. The number of articles on tactile graphics in 2019 and 2020 were 7 and 10, respectively, which was more than those in other years, as shown in Figure 5. It is clear, as shown in Figure 5, that in recent years, there has been a growing focus on creating tactile graphics for the blind.

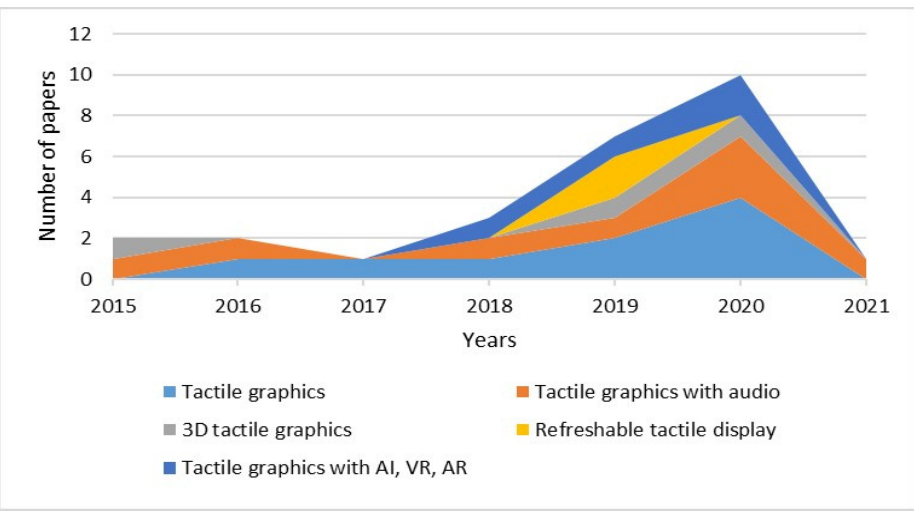

Figure 5. Selected papers for review by technology and year. 
Technologies and Venues

According to these selected articles, it was determined that BVI individuals used traditional tactile graphics ( 9 articles), tactile graphics with audio ( 8 articles), 3D tactile graphics ( 3 articles), refreshable tactile display ( 2 articles), tactile graphics with AI, virtual reality (VR), and augmented reality (AR) (4 articles) to perceive visual information (Figure 4). A comprehensive review of these articles revealed that technologies such as audio and 3D modeling, which are closely related to tactile graphics, received considerable attention among researchers for delivering visual information to BVI individuals.

The final corpus contained 26 papers from nine unique sources. For easier understanding, we have combined journals and conferences that belonged to a single electronic database, digital library, or open-access publisher under a single name. For example, ACM CHI, ACM ASSETS, ACM TACCESS, and others were categorized as ACM. The most extensive collection of papers was from ACM (11 papers, 42\%). As shown in Figure 6, only one paper was collected from each of four sources: Sensors and Materials, Journal of Science Education, KSII T Internet Info, and Universidad de los Andes (totaling four papers, $16 \%$ ).

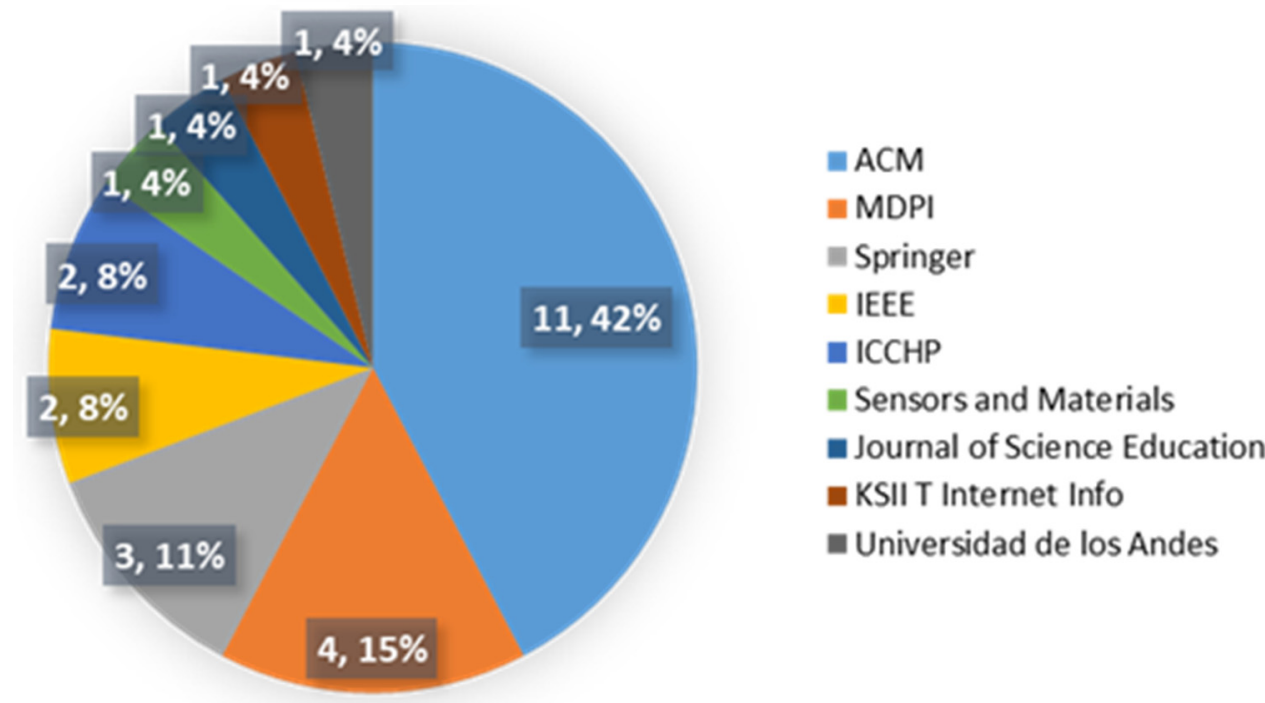

Figure 6. Number of selected papers according to electronic database and digital library or openaccess publisher.

The majority of articles obtained were categorized as full papers by their source. Additionally, some articles were considered to be accompanying poster papers or short papers. Short papers do not typically expect the same uniformity of reliability in the assessment and include things such as initial research. Most of the short and poster papers were obtained from ACM ASSETS; hence, they can be considered full papers (Figure 7).

Throughout the full-paper screening, descriptions were written to decide which of the research questions were answered by the 26 selected studies. More than $84 \%$ of the selected articles provided answers to RQ1, while $46 \%$ provided answers to RQ2. Moreover, approximately $20 \%$ of the selected articles responded to RQ3 (Figure 8). 


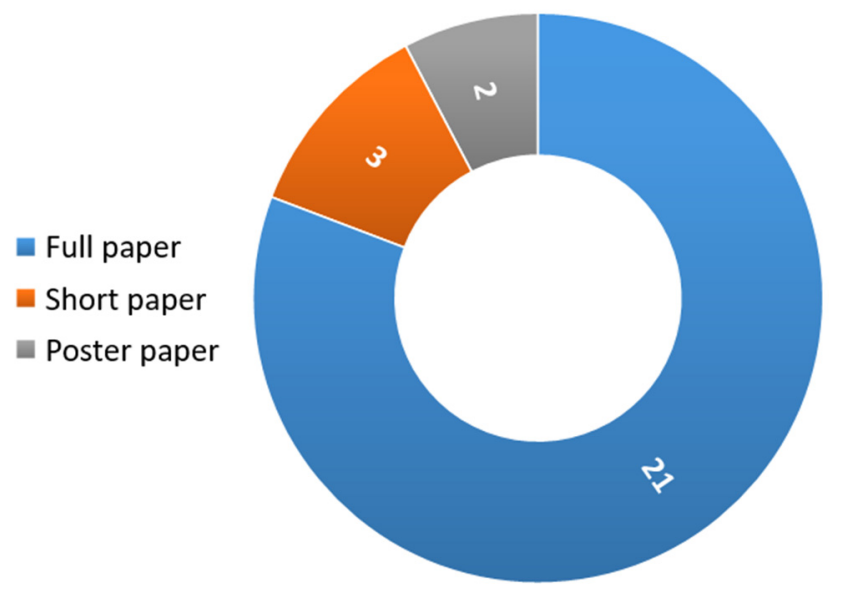

Figure 7. Number of papers by type.

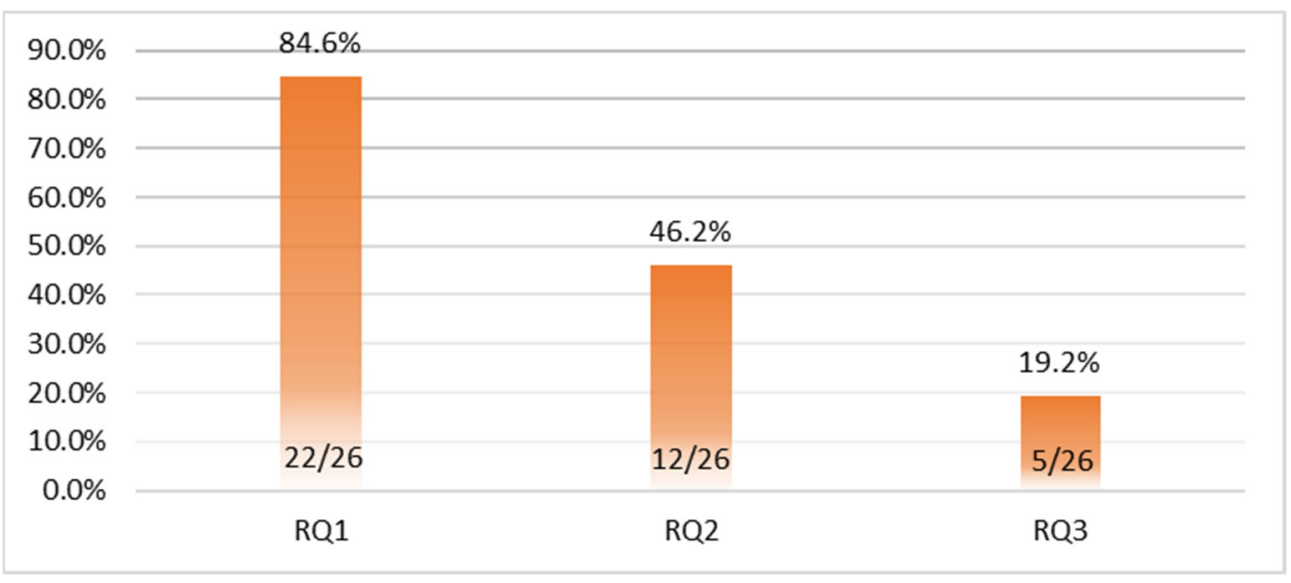

Figure 8. Percentage of selected studies that provided answers to the three research questions.

4.4. Research Question 1: What Is the Role of Tactile Graphics in the Education of BVI Individuals and Their Adaptation of the BVI to the Society?

The importance of using tactile graphics in education and social life was discussed in most of the primary studies. The use of images and diagrams in educational materials, particularly in STEM subjects, was considered necessary. Accordingly, it is widely accepted that producing graphical information accessible to BVI students would significantly enhance their educational and career opportunities. In recent years, there has been an increasing number of scientific studies on tactile graphics generation and their application to diverse subjects or the adaptation of BVI individuals to daily life.

\subsubsection{The Role of Tactile Graphics}

A full analysis of the articles revealed that almost half of the primary studies on education (14 papers) and the other half (12 papers) contributed to the adaptation of BVI individuals to the society (Figure 9). Among the current technological advances, the role of tactile graphics technologies in the education and social life of BVI individuals cannot be replaced by other means (Figure 9). 


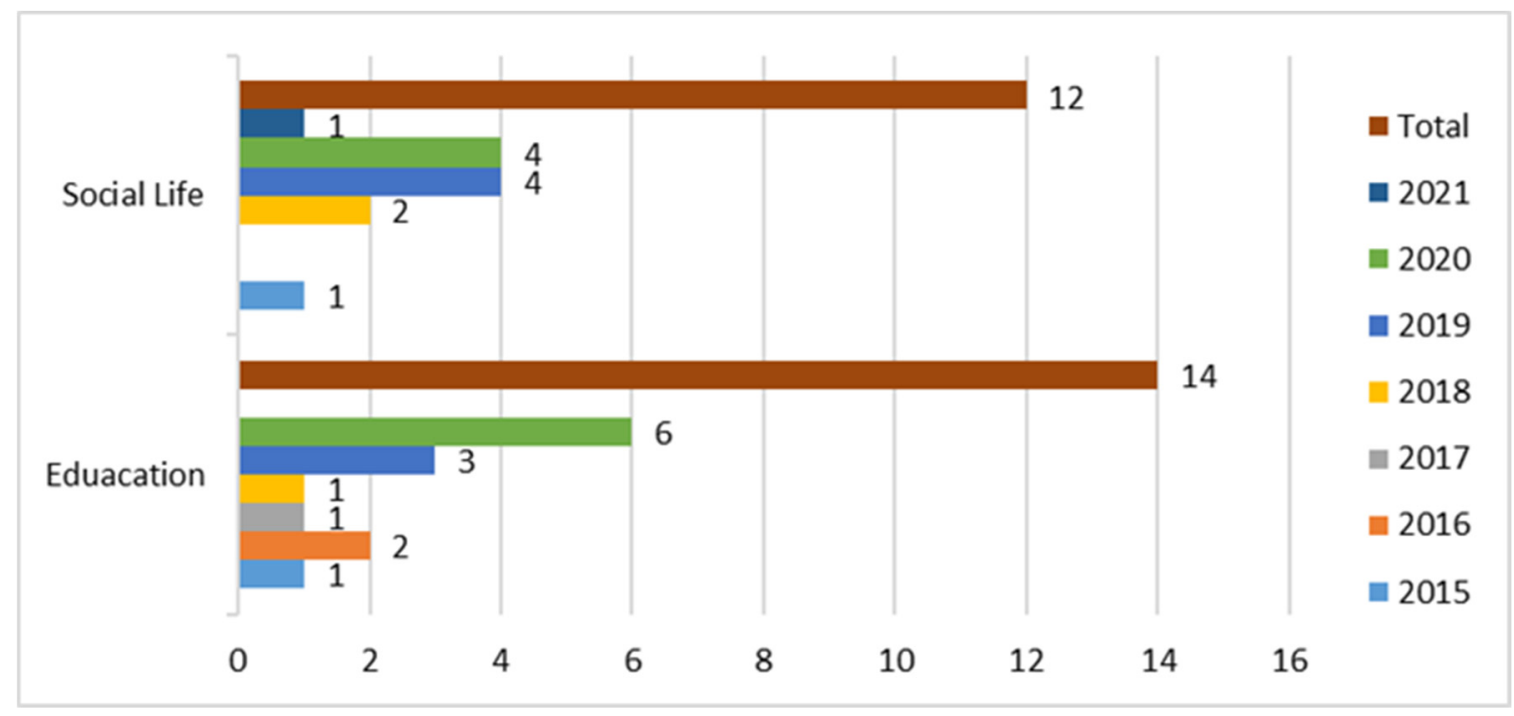

Figure 9. Number of primary papers based on the social life and education of BVI individuals (in years).

The tactile graphics that were introduced in primary studies for assisting BVI users are summarized in Table 3. The bulk of the tactile graphics used in education were designed to understand STEM subjects (8 papers), followed by braille books and images (2 papers). The rest of the electronic circuits, HTML web pages, computer science, and physics fields were covered in one article each, respectively. Furthermore, while traveling and creating tactile graphics from natural scene images has been one of the dominant fields in adapting to social life (5 papers), only three articles aimed to support map and audio guidance field.

Table 3. The role of tactile graphics for use in a variety of fields.

\begin{tabular}{|c|c|c|c|}
\hline Tactile Graphics' Role & Field Name & Number of Papers & Articles \\
\hline \multirow{6}{*}{ Education } & STEM subjects & 8 & {$[11,21,48-53]$} \\
\hline & Braille books with images & 2 & {$[54,55]$} \\
\hline & Electronic circuits & 1 & [56] \\
\hline & HTML web pages & 1 & [38] \\
\hline & Computer science and physics & 1 & [7] \\
\hline & Virtual reality objects & 1 & [57] \\
\hline \multirow{5}{*}{ Social Life } & Travelling and tactile graphics & 5 & {$[35,36,58-60]$} \\
\hline & Map and audio guidance & 3 & [61-63] \\
\hline & Artworks and object's shape & 2 & {$[64,65]$} \\
\hline & Haptic and braille display & 2 & {$[31,66]$} \\
\hline & Orientation and Mobility & 1 & {$[62]$} \\
\hline
\end{tabular}

We identified types of input images to generate tactile graphics, as shown in Table 4. General images, such as natural scene images, were used the most ( 9 papers), followed by charts and diagrams (7 papers). These types of images can be used in the educational and social life of the BVI. Interestingly, geometric figures were used in five papers, while SVG images and book pages were utilized to make accessible web pages or educational materials (3 papers), respectively. Visual artworks were used in two papers, maps in two papers, and only one used images of electronic circuits, biological molecules, or node-link diagrams. 
Table 4. Types of input images to generate tactile graphics.

\begin{tabular}{ccc}
\hline Input Image Type & Number of Papers & Articles \\
\hline General images & 9 & {$[31,35,36,55,58-61,65]$} \\
\hline Different charts and diagrams & 7 & {$[11,21,31,48,51-53]$} \\
\hline Geometric figures & 5 & {$[35,53,57,60,66]$} \\
\hline SVG images & 3 & {$[7,38,63]$} \\
\hline Book pages & 3 & {$[21,54,66]$} \\
\hline Visual artworks & 2 & {$[64,65]$} \\
\hline Maps & 2 & {$[62,63]$} \\
\hline Electronic circuits & 1 & {$[56]$} \\
\hline Biological molecules & 1 & {$[49]$} \\
\hline Node-link diagrams & 1 & {$[50]$} \\
\hline
\end{tabular}

A brief summary, including information on article technology, tactile graphics in education and social life, tactile graphics generation methodology, experiments and evaluation, and results and conclusion of each primary paper, is presented in Appendix A.

\subsubsection{Tactile Graphics for STEM Subjects and Braille Books}

To the best of our knowledge, one of the current problems confronting BVI individuals is the lack of teaching materials in the field of education, especially in STEM subjects. Several primary studies, such as $[11,49,50,56]$, presented different approaches as a solution to this problem. Fusco and Morash [11] introduced a machine vision-based tactile graphics helper (TGH), which followed the fingers of blind students as they investigated tactile graphics and enabled them to obtain refined audio messages regarding the tactile graphics without sighted assistance. Show and Hadden-Perilla [49] developed a software plugin to quickly produce variable-height tactile graphics of proteins using the free biomolecular visualization software, Visual Molecular Dynamics, and protein structure data. The software plugin could be used in scientific disciplines spanning biology, biochemistry, and biophysics, relying on an understanding of protein structure to explain the mechanisms by which proteins carry out their functions. The software plugin could also be used to classify strategies by which those functions can be improved or changed to heal diseases and improve human health. Yang et al. [50] conducted a controlled study with BVI participants and compared four tactile network representations: organic node-link diagrams, grid node-link diagrams, adjacency matrices, and braille lists. Network forms are usually utilized to study and represent social networks, biological networks, and software in popular media. Park et al. [54] proposed a method for automatically converting print books into electronic braille books based on algorithms for categorizing and analyzing images scanned from print books. Their method was intended to reduce the time and cost needed to design braille books and provide more study materials for BVI individuals, advancing notable contributions to improving their education and social life. The system responded to questions regarding STEM tactile graphics, such as "what is on this tactile graphic?" and "what is this I'm pointing to?" Race et al. [56] created a more observable collection of schematic symbols for a popular textbook, and proposed a set of guidelines and the best methods for teachers and designers to create their readable tactile schematics. The readable tactile version of six schematics, which is essential for learning electronics basics (battery, switch, resistor, and others), was completed after 11 rounds of iterations based on the recommendations of blind participants.

\subsubsection{Involvement of Blind and Visually Impaired}

Visual status of participants. Almost two-thirds of the papers (18 papers) in the main corpus evaluated the benefits of creating tactile graphics and experimented with visually 
impaired participants. Overall, a total of 143 BVI people, 78 females and 65 males, participated in all experiments of 18 papers. Of these participants, 68 were blind, 51 were blind with some vision, and 24 had low vision. Additionally, in the remaining six papers, the experiment was conducted and evaluated without the participation of visually impaired participants; however, in two papers, experiments and evaluations were not conducted.

Age of participants. Most of the papers that evaluated and experimented with BVI individuals provided complete information regarding the age range and gender of the participants, and only five papers did not specify such information. However, those five papers stated that the participants were school, college, or university students, or over 18 years of age. Based on the papers in which the age of the participants was clearly presented, the youngest and oldest participants were 11 and 84 years, respectively. The median age of BVI participants was 47.6 years old.

Gender of participants. Presenting information on the gender of visually impaired participants is as important as their age. Although the gender of the participants was not frequently stated, most of the papers presented the number of male and female participants. Approximately half of the primary studies (13 papers) reported gender information. Based on the demographics in these articles, the number of female participants was slightly higher than that of males: 78 and 65 , respectively.

We summarized the involvement of BVI in the system development and evaluation processes in Table 5. We divided the experimental processes into four main parts: design, evaluation, concept, and no user study, according to methodology of system. As a result, we determined that 18 studies had used BVI people in their experiment and subjective assessment.

Table 5. BLV's involvement in system design and evaluation.

\begin{tabular}{cccr}
\hline Methodology & Type of Process & Number of Papers & Articles \\
\hline Participatory Design & Design & 2 & {$[52,60]$} \\
\hline Experiment \& Subjective Assessment & Evaluation & 18 & {$[7,11,21,48,50-54,56-59,61-65]$} \\
\hline Interview \& Survey & Prototype & 4 & {$[11,21,63,64]$} \\
\hline N/A & No user study & 8 & {$[31,35,36,38,49,55,60,66]$} \\
\hline
\end{tabular}

\subsubsection{Involvement of Sighted Teachers and Instructors}

Three studies also included sighted teachers and instructors for creating tactile graphics and conducting experiments [7,60,63]. Melfi et al. [7] introduced an audio-tactile TPad system for an educational environment that combined a touchpad, a tactile graphic, and an accessible app. They also designed a questionnaire to study the experiences of two sighted teachers. The TPad system was discussed with the teachers by asking them eight open-ended questions regarding their opinions before the study, and the workflow for utilizing it in the classroom was presented: creating a tactile version of a sample graphic from a school book with LibreOffice Draw, uploading a file to the repository, demonstrating the functionalities of the repository's web interface, and simulating the use of the system in the classroom.

Surprisingly, Stangl et al. [60] investigated how six caregiver stakeholder groups with 69 participants, including accessibility librarians (7), children's librarians (8), talking book library volunteers (7), hacker engineers (3), interaction designers (4), orientation and mobility (O\&M) specialists, and teachers of the visually impaired (40 specialists and teachers), attempted to produce purposeful 3D printable accessible tactile pictures with amateur-focused 3D modeling programs. Thevin and Brock [63] introduced a novel AR method that allowed learners to efficiently and instantly augment real objects with audio feedback. In their method, three O\&M instructors and three different teachers (biology teacher, tutor, and primary school teacher) were asked to augment an existing tactile map of the school and a tactile biological atlas. 
4.4.5. Advantages and Disadvantages of Existing Solutions in Education and Adaption of BVI

Tactile pad and tablet. In the given set of primary studies, we also identified differences, advantages, and disadvantages of existing solutions in education and adaptation of BVI people. Although the goal of the above studies was the same, the solutions were different. The variety of solutions allowed us to compare the advantages and disadvantages of each study. The interactive audio-tactile method using the TPad system [7] accelerated the learning process of BVI students more than 2 times with 111 s, while Digital Key and Braille Key methods performed well, with an an average exploration time of 277 and $359 \mathrm{~s}$, respectively. However, the Tpad system could increase the workload of teachers since only a few teachers know how to create tactile graphics using a Braille embosser. Furthermore, this system's management requires funding sources and a new workplace from schools because it consists of a touchpad, tactile graphics, and accessible applications. A similar solution, namely, a TGH tablet [11] was proposed to explore tactile graphics using image segmentation and edge detection techniques. It had the main advantages of helping blind users with voice communication and giving information about the tactile graphic, such as details about what the user was pointing to. However, for a TGH to work properly, a matrix map that associates every pixel in the graphic with a label ID and a YAML file describing the attributes associated with each label ID are required.

Diagrams and graphs from school textbooks. Scientific diagrams, such as biological molecules [49], and node-link diagram [50], an electronic circuit [56] enable BVI students to research with their sighted peers. The software plugin to convert proteins into tactile graphics was developed with the advantages of running on Windows, Mac, and Linux operating systems and has been made accessible to BVI through its text console interface, which can be used with a screen reader or Braille display [49]. However, this plugin takes advantage of Visual Molecular Dynamics (VMD) software package and requires blind users to install and work with VMD. It also requires a prebuilt 3D protein structure, which can be a difficult task for teachers and researchers. The use of note-link representation in the conversion of social network visualization from educational materials to tactile graphics was deemed the most effective way to identify the connection between two networks [50]. We also found that the small sample size and the lack of variability in the graphs may have prevented the study and results from being complete and accurate. Another absorbing study to generate tactile graphics from Braille book had the advantages of identifying text areas and image areas separately using computer vison techniques [54]. Although the text in the books were converted to Braille with high precision, various problems in creating tactile graphics from complex shaped images were not solved. A microcapsule fuser and paper were used to create a tactile graphic of the schematics in school textbooks [56]. However, the process was static and required different settings and human interaction for each electronic circuit.

$3 D$ and AR tactile graphics for blind children. An issue that was tackled by Stangl [60] involved organizing workshops with representatives of various fields who wished to help BVI children and conducting experiments and interviews on 3D printable tactile graphics. Because most of the participants in this workshop did not have sufficient knowledge of 3D modeling and tactile graphics, some of the results were incomplete and not tested with blind children. The ability to create audio-tactile graphics for blind children from real objects using augmented reality methods brought a new direction to the field [63]. It has the advantage of allowing teachers to design their pedagogical audio-tactile content from existing real objects. However, it takes time for school teachers to fully explore this system and additional funding sources from schools to implement it in classrooms.

\subsection{Research Question 2: What Are the Current Methods and Commercially Available Technologies for Dynamic Tactile Graphics Generation?}

The review showed that there were numerous solutions for dynamic tactile graphics generation for BVI individuals. Many of these solutions have been practiced in real life and are commercially available. However, some studies have not been implemented. We tried 
to explain this by analyzing the studies in the primary corpus to generate tactile graphics and the most popular programs and technologies among BVI individuals on the Internet as shown in Table 6.

Table 6. Currently available tactile graphics creation methods, software and hardware.

\begin{tabular}{ccc}
\hline Tactile Graphics (TG) Creation & Currently Available Method & Commercial Software and Hardware \\
\hline General image to TG & {$[35,36,55,58-61,65]$} & {$[67-73]$} \\
\hline Book to TG & {$[21,54,66]$} & {$[72-74]$} \\
\hline Web pages to TG & {$[7,38,63]$} & {$[72]$} \\
\hline Chart and diagram to TG & {$[11,21,31,48,51-53]$} & {$[67,68,70,72-74]$} \\
\hline Art and culture to TG & {$[64,65]$} & {$[72-74]$} \\
\hline Map and plan to TG & {$[62,63]$} & {$[67,68,70,73]$} \\
\hline Figure to TG & {$[35,53,57,60,66]$} & {$[67-72,74]$} \\
\hline Audio feedback support & {$[21,51,52,61,64]$} & {$[67,68,70,72-74]$} \\
\hline Tactile display support & {$[31,58,59,66]$} & {$[67,68,70,72-74]$} \\
\hline
\end{tabular}

\subsubsection{Currently Available Platform and Framework}

The 2020 issue of the ICCHP, which has been held every two years since 1989, supports the advancement of information and communication technology and AT for people with disabilities and the aging population. It has a special section for creating tactile graphics and models for blind people and recognition of shapes by touch. Maćkowski et al. [53] developed a platform that was not only designed to share the visual information used in mathematics but also to provide BVI individuals with self-learning in a step-by-step process, followed by evaluation of their development as students by a teacher or a psychologist. The most notable progress was observed in the category of concept acquisition and selection of information, which translated into improving the experiences of problem-solving and selfdevelopment of mathematical skills. Bose et al. [38] introduced a framework that accepted simple HTML web pages that included only graphics in scalable vector graphics format or a combination of text and graphics. The framework contained four modules: filtering, classification, transformation, and audio. The transformation module was responsible for generating the tactile representation of graphics to be displayed on a tactile device or embossed paper. Unfortunately, their platform [53] and framework [38] have not yet been implemented in practice and are not commercially available.

\subsubsection{Currently Available Methods from Images}

JinSoo Cho and his research team presented an interesting project in the field of AT and tactile graphics generation for BVI individuals [31,54,58,59,66]. Meanwhile, Yoon et al. [58] introduced a new method for extracting salient regions based on global contrast enhancement to improve the process of recognizing natural scene images for BVI individuals. In the method, the contours of the salient regions were detected and translated into tactile graphics so that a BVI individual could perceive it using a refreshable braille device or printed swell paper. Abdusalomov et al. [59] proposed a saliency cuts method using local adaptive thresholding to obtain four regions from a given saliency map [58]. In the method, the salient object is cut and the outer and inner edges of the salient objects are detected so that a BVI individual can effortlessly understand the content of an image. This method was implemented in production and education processes in the training laboratory of a specialized boarding school for the visually impaired by printed tactile graphics using the Index Braille Embosser.

\subsubsection{Currently Available Methods from Electronic Books}

Kim et al. [66] described a methodology for effectively converting multimedia content, DAISY, and EPUB formats to braille, as well as correctly rendering and displaying text, 
images, audios, and videos on a 2D multi-array braille display. This new 2D multi-array braille display technology is efficient for BVI individuals as it expands their access to learning and supports navigation through multimedia content. From an educational viewpoint, the 2D mobile braille display can be beneficial for obtaining information such as scientific figures, natural scene images, literature, and audio-based education [66]. Kim et al. [31] concentrated on the development of a 2D multi-array braille display utilizing an electronic book translator application because of its accuracy and high speed. To share multimedia content, they presented a braille electronic book reader application that could share a large number of figures, text, and audio content. Meanwhile, Tactile Pro and Tactile Edu mobile tablets and Braille Contents Author software were created for BVI individuals by combining the methods and technologies $[10,31,54,58,59,66]$.

\subsubsection{Currently Available Methods Using Audio}

Furthermore, we identified solutions created to develop tactile graphics using audio. Baker et al. [21] proposed a new system for embedding and accessing text in tactile graphics by applying $Q R$ codes, which are small codes that quickly encode textual information. $\mathrm{QR}$ codes can be read by a smartphone application that scans $\mathrm{QR}$ codes and provides feedback to help BVI users. If more than one QR code is visible, it requires information to determine which $Q R$ code must be scanned. Therefore, finger pointing was implemented to differentiate which label to scan. Engel et al. [51] introduced a software to increase the generation method and quality of tactile charts with audio. The current implementation involves an accessible graphical user interface that supports well-designed default parameters for tactile chart generation. Their generation process was divided into five basic parts: (1) the input data, which are the raw data presented in the chart; (2) the user input, which specifies characteristics that can be set or triggered by the user inside the user interface; (3) the user interface that provides an interactive SVG file within the preview; (4) the rendering process, which receives the input data from the user interface to generate the output data presented to the user; and (5) design guidelines, which highly depend on user input, particularly on raw data [51]. Chase et al. [52] proposed a system that provided audio and haptic direction through skin-stretch feedback to the dorsum of a BVI's hand, while exploring a tactile graphic overlaid on a touchscreen. The system was able to support two teaching scenarios (synchronous and asynchronous) and two guidance interactions (point-to-point and continuous) and demonstrate their use in two applications: a bar chart and tactile graphics of a marble rolling down an inclined plane. Hashimoto and Takagi [61] developed an audio-tactile graphic software executable on smartphones to overcome the limitations of current audio-tactile graphic systems. The system had some limitation: (1) the system required for specialized devices that were often costly; (2) the system required users to generate particular tactile graphics to the software because existing tactile graphics were not available to the current software; (3) considering that specialized devices were large, this limited the portability of the systems. Cavazos et al. [64] presented an interactive multimodal guide prototype that consisted of a touch-sensitive $2.5 \mathrm{D}$ artwork relief model that used audio and tactile graphics to enhance independent access to visual information and knowledge of visual artworks. The current prototype was created for practice in an exhibition context. School art teachers showed interest in applying the design as an educational instrument in the classroom. As a result of the analysis, additional audio feedback was proven to be an effective method for making it easier for BVI individuals to perceive tactile graphics $[7,11,51-53,61,64]$.

\subsubsection{Commercially Available Software and Hardware}

We also found several AT software and hardware systems that are now commercially available. While many of them have been competing in the market for several years, some have contributed to the development of AT with new technologies in the last five years. Thinkable [67] has been manufacturing several applications and devices for many years. They specialize in products and services to create tactile graphics, and their products 
are well known among BVI individuals, such as TactileView drawing software, TactiPad with drawing tools, Motorized Drawing Arm, GraphGrid, and RouteTactile. The American Printing House for the Blind [68] provides a tactile graphics kit, which includes a comprehensive set of elements that enable teachers, transcribers, and mobility instructors to generate custom raised-line graphs, maps, diagrams, and charts. American Thermoform [69] is one of the leaders providing tactile graphics machines and supplies such as the Swell Form Graphics Machine, Swell Touch Paper, and Swell Touch Pens. ViewPlus [70] developed an IVEO software that enables users to experience tactile graphics in an appealing and interactive manner. Consisting of powerful content generation software and an intuitive touchpad for an audio-tactile response, IVEO provides unparalleled access to tactile information. SeeWriteHear [71] produced tactile graphics with specific devices capable of generating a wide range of textures and relief levels, along with control braille descriptions and titles for education and government. PCT [72] created the world's first blind-only tablet PC (Tactile Pro and Tactile Edu) to print braille and tactile graphics in real time, as well as numerous applications, including games, internet, editing documents. They also developed input and output devices for a braille input and a tactile display. Orbit Research [73] developed a refreshable tactile graphics display to address the difficulty of rendering on-screen graphics for BVI individuals. The device enables users to obtain a broad type of on-screen graphics by touch, for example, different charts and graphs, maps, geometric forms, line drawings, and dynamic graphical content. Bristol Braille [74] produced Canute 360, a nine-line refreshable tactile graphics display to generate graphs, charts, musical notation, mathematics, tables, and special diagrams for schools and educational institutions of the blind.

\subsubsection{Currently Available Online Tutorials}

We found it interesting that many publications and internet posts were aimed at creating tactile graphics and teaching them among the blind. Many of them were special schools and centers for BVI individuals, as well as various organizations around the world, such as the World Blind Union, and six regional organizations, National Federation of the Blind, American Foundation for the Blind, American Printing House for the Blind, Braille Authority of North America, National Industries for the Blind, Perkins School for the Blind, Light House for the Blind and Visually Impaired.

\subsubsection{Intended Application Domains}

We classified the intended application domains of articles in the main corpus and commercially available technologies by analyzing them. The results of the analysis revealed that the focus on education and daily routine domains remained high in 26 and 17 studies, respectively, followed by orientation and mobility, with 6 studies each (Table 7). There was little interest in the work environment or museum and art domains. We believe that these will be among the most dominant areas of future research and will focus on sports activities (which are not currently available for BVI people) with new solutions.

Table 7. Intended application domain of currently available methods, software and hardware.

\begin{tabular}{ccr}
\hline Intended Application Domain & Number of Papers & Articles \\
\hline Education & 26 & {$[7,11,21,31,38,48-60,66-74]$} \\
\hline Daily routine & 17 & {$[31,35,36,38,54,55,58-60,63,65-70,72]$} \\
\hline Orientation and mobility & 6 & {$[60-62,67,68,73]$} \\
\hline Work environment & 5 & {$[54,60,61,71,72]$} \\
\hline Museum and art & 4 & {$[60,64,65,74]$} \\
\hline Other & 5 & {$[36,37,67,69,72]$} \\
\hline
\end{tabular}


A word cloud generated using words written in the titles and abstracts of papers in the primary corpus is shown in Figure 10. It depicts the range and concentrations of terms found in study titles and abstracts. Words that appear more frequently have a greater weight.

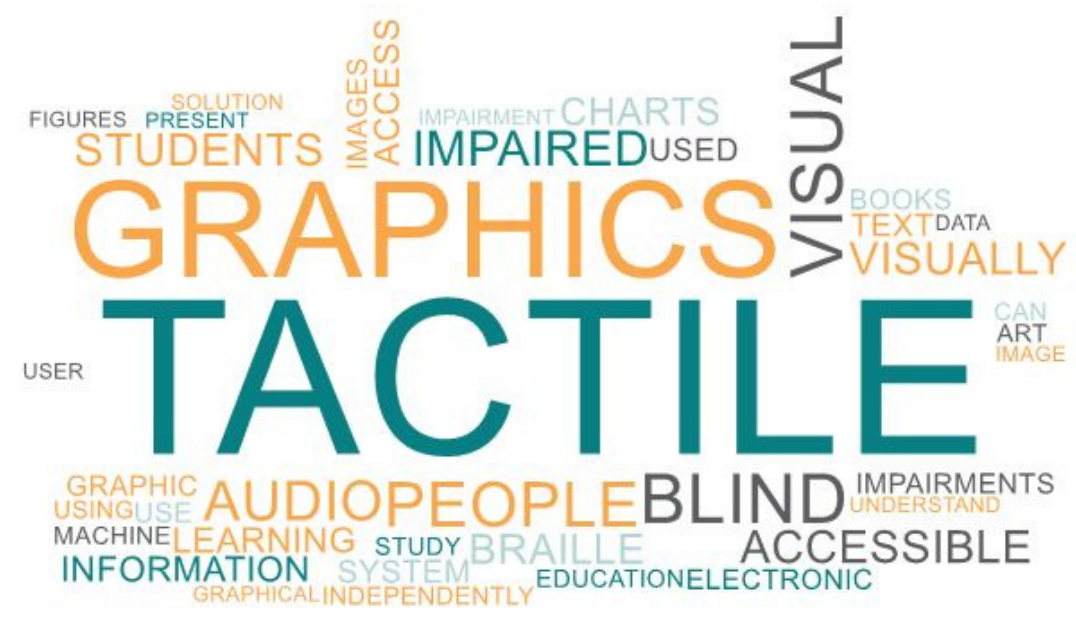

Figure 10. The most frequent terms in tactile graphics generation for the BVI people based on our selected primary studies. Max word limit is 40 .

\subsubsection{Advantages and Disadvantages of Current Methods}

$2 D$ multiarray braille display. Due to the development of embedded systems and smartphones, static tactile graphics are being replaced by dynamic 2D braille displays. The main advantage of a 2D multiarray braille display is that it can display text content, painting, photographs and mathematical expressions from electronic books or online documents in a short time via a refreshable braille cell $[31,38,66]$. An operating system and software package were developed for converting texts and images into braille text and tactile graphics. Although the developed operating system and software packages were tested in an Android-based simulator [31,66] or online website [38], the developed 2D multiarray braille display was not used for experimentation and evaluation with the blind. Hopefully, in the future, BVI users will be able to evaluate such 2D Braille displays, and the results will be made public.

Tactile graphics from natural scene images. One of many challenging tasks for the visually impaired is to perceive objects which are located in real-life environments during traveling. To address this problem, salient object extraction methods [58,59] have several advantages, e.g., creating a mental map, analyzing the situation, and moving independently by perceiving surrounding objects. But this is only the software part of the system, and a hardware part, such as a 2D multiarray braille display or Tactile tablet, is also required to perceive the contours of objects in real-time. Purchasing such assistive devices creates a challenge for low-income users.

Tactile graphics with voice. Another effective way of delivering visual information to BVI users in real-time is to use audio descriptions. For the blind users who do not know the Braille alphabet, the method of using QR codes instead of texts on mathematical graphs and charts is notable for its simplicity and modernity. The advantage of this method is that the overall process is similar to the creation of traditional tactile graphics, only the texts are converted to QR code rather than the Braille alphabet. However, an application was created for smartphones to read QR codes, which is required when perceiving tactile graphics. Additionally, because current braille embossers cannot print ink, QR codes had to be printed on a separate sheet of paper and glued onto the tactile graphic. In the last three years, the interactive use of tactile graphic, audio and haptic methods to explain school teaching materials to blind students has been deemed an effective research direction by many scholars $[51-53,61,64]$. Creating different charts and converting them to a tactile 
graphic with software that has an easy and convenient graphical user interface is not be a problem, even for teachers without a good understanding of computers [51]. In addition, an audio-tactile tablet or an interactive audio-tactile pin matrix device can be used to interact with the graphics. One of the device's drawbacks is that the user interface is only available in the German language and does not support other languages. Haptic guidance was also created as an aid to audio information in the teaching process in [52]. Their device has the advantage of helping students understand complex mathematical charts and graphs through haptic point-to-point directional cues. The experiment showed that, when the haptic cue was not coordinated with the audio, blind students had some difficulty focusing on either the haptic cue or the audio. Placing tactile graphics on an Android-based tablet and providing additional audio information by detecting touchscreen pressed points has the advantage of applying a new interactive method to the teaching process of mathematical exercises at a lower cost [53]. Additionally, teachers are able to send digital audio-tactile pictures to the tablet of blind students and evaluate, monitor their learning progress through the developed web teacher application. However, such approaches require blind students to purchase tablets or schools to set up special interactive classrooms. The use of audio description in understanding tactile map [61] and 2.5D tactile artwork models [64] plays an important role in the independent movement of the visually impaired and their perception of visual artwork. This tactile map with accompanying smartphone application [61] is one of the cheapest solutions in determining the location of rooms in school buildings and large buildings. However, for the smartphone application to work accurately, it is necessary to create a simple tactile map, and this is complicated by the complexity of the location of rooms in many large buildings. The method of adding audio tags to a $2.5 \mathrm{D}$ tactile artwork gives art-loving blind people the advantage of perceiving visual artwork and listening to audio information synchronously [64]. This system allows the blind to hear information about artworks by simply touching them without reading the Braille texts. In practice, at an exhibition, interactive zones in some of the artworks lacked ambient audio information. Audio information should be added to the interaction zones that lack audio records, e.g., background or space, to control blind users' expectations.

\subsection{Research Question 3: What Are the Advantages of Solutions Using AI and 3D Printer and the Gaps That Need to Be Addressed for Future Developments?}

$\mathrm{AI}$ and machine learning are now being adopted in almost every field, and their benefits are enormous. When the source image is extremely complicated, tactile graphics require accuracy, which can confuse visually impaired people. Each image to be transformed must be carefully reviewed to ensure that it is a reliable representation of the image's content. Therefore, a method is required to convert any complicated image into a simple, straightforward design that can be represented through tactile graphics. Recent advances in $\mathrm{AI}$ and machine learning can assist researchers and developers in achieving such a solution [75].

\subsubsection{Use of VR and Deep Learning}

The importance of using AI and machine learning methods for creating automatic tactile graphics generation was stated in [36]. Asakawa et al. [57] developed tactile educational tools for presenting the shapes of objects to BVI individuals using VR. The system used optical capture and a haptic device to solve the problem of the dynamic capability of the tracker device. Moreover, optical capture was utilized to identify the position and posture of the hand, and a haptic device was applied to provide tactile response to a user in a virtual space. A haptic device was developed using a servo motor as an actuator and a finger pad. Felipe and Guerra-Gomez [35] presented a framework that used machine learning to analyze the quality of web and personal images and categorized them into different classes. The framework was very effective for teachers and parents of BVI individuals in testing whether images were suitable for creating tactile graphics. The machine learning model used Google Cloud AutoML for training, and several iterations were performed to achieve better results. In the first training, 1400 images were used as positive samples and 
1400 images as negative samples. The results were unsatisfactory because of the presence of braille annotations in the positive examples. Afterward, a new dataset, comprising 321 images as positive samples and 753 images as negative samples, was manually created according to experts' guidelines. However, the results still required more improvement in the trained and testing sets. Finally, 655 images were added to the model, of which 96 images were positive samples and 559 images were negative samples. Although the resulting software and machine learning model had some drawbacks, the use of machine learning in generating AT for BVI individuals was noteworthy. Gonzalez et al. [36] introduced a web platform that included (1) images that were transformable to tactile graphics and (2) an online learning model where users were able to classify whether an image could be transformed into tactile graphics - and where teachers of the visually impaired (TVI) could retrain the model. The model was built on top of MobileNet because it is a well-proven model for classification tasks. The web platform has three pages: a training page, a search page, and an evaluation page. On the training page, TVI can access unclassified images, and users can upload and confirm that the images are tactile graphics transformable images. On the search page, users can access the classified images and upload images to determine whether they are suitable or unusable for conversion to tactile graphics. On the evaluation page, users can view the evaluation result of the image uploaded to classify and download the image along with access to the training page if the result is incorrect.

\subsubsection{Use of 3D Printing}

Panotopoulou et al. [65] addressed a problem; namely, the successful modeling of 3D objects that supposes the identification and combination of important data in topology and geometry. First, a general pipeline was built for the design of tactile models to increase the 3D shape perception of BVI individuals. Afterward, a user study was designed to assess the effectiveness of the models, in which a selection of household objects was implemented. Tactile models can be utilized as a tool to represent products, from furniture in a store catalog to art pieces in a museum to object repositories for 3D printing. A similar shapeunderstanding problem was discussed by Holloway et al. [62]. Representational 3D printed maps and icons may be useful for wayfinding while navigating an event, and they can be readily recognized by touch even without experience or confidence using tactile maps. It was the first in-the-wild paper of 3D maps and icons for BVI individuals. Thus, the research has had a significant impact on O\&M instructors, creating professional guidelines for the use and design of available 3D prints and identifying the potential role of 3D maps for access and inclusion.

\subsubsection{Advantages and Disadvantages of AI and VR Based Methods}

Visual image categorization using machine learning. For automatic translation of visual images into tactile graphics methods, it is important to determine the level of complexity of the input image. The advantage of web platforms $[35,36]$ that divide visual images into easy, medium, and complex categories by analyzing the contours of images applying computer vision and machine learning models is that tactile graphic creators can find the desired image from the database or check the complexity of existing images without spending much time. The main drawback of these systems is that they have not yet been implemented in real life and misclassify some images, as the authors stated. By retraining the machine learning model with a large number of images belonging to different classes, it is possible to improve the quality of accuracy and classify the objects in the various classes.

$2 D$ and $3 D$ tactile object and VR. In contrast to the above work, creating $2 \mathrm{D}$ tactile illustrations of 3D geometry of daily objects for the blind is extremely challenging [65]. It has the advantage of converting different kinds of 3D objects—such as furniture, textbook models and museum exhibits-into tactile graphics using a master camera in a short time. However, the main disadvantage of this method is that it ignores the useful details of complex objects, and there is no good approximation of bowl and circle objects through the 1D skeleton. Additionally, the current version of this method [65] has no integration with 
interactive tactile graphics, e.g., combined with interactive audio feedback, refreshable tactile graphics displays, or dynamic markers. 3D maps and signs are widely utilized for BVI people to have the skills to move around safely and to create the conditions for independent living by introducing them to the local environment, new places, and routes before traveling [62]. This 3D map and icon creation method applied the traditional time-consuming semiautomatic approach and required separate work for each building map, icon and object. All of the above works were for still objects, and the blind could not understand moving or growing and changing objects such as rolling balls, fluttering curtains, flying insects, plants, animals, and organisms. Using VR technology, the BVI user feels tactile sensation on the object by touching the surface of the virtual object [57]. Some limitations of this VR system are as follows: it was challenged in recognizing the shape of objects because BVI individuals sense using only two fingers, and the system's response time could be too slow to accurately reflect reality.

\subsubsection{Summary for RQ3}

To the best of our knowledge, the currently developed AI and machine learning methods, platforms, and applications for mobile phones are not sufficient for the BVI community. Based on our systematic review results, we can conclude that AI and machine learning methods have been applied to the field of technologies that help BVI individuals in the last three years but still require extensive research and development (Table 8).

Table 8. AI- and 3D printing-based methods.

\begin{tabular}{|c|c|c|}
\hline Type of Solution & Method & Articles \\
\hline \multirow{2}{*}{ Deep learning } & Image categorization using Cloud Vision Auto ML model & [35] \\
\hline & Image classification using MobileNet model & [36] \\
\hline \multirow{2}{*}{ 3D printing } & 2D graphics from 3D objects using multi-projection rendering & [65] \\
\hline & 3D maps for orientation and mobility training & [62] \\
\hline Virtual reality & Touching object shapes using optical motion and haptic device & [57] \\
\hline
\end{tabular}

\section{Discussions}

From the full-text review, we can conclude that most of the existing solutions in the field of automatic tactile graphics generation were reported in studies conducted between 2015 and 2020. This is particularly true when creating tactile graphics with audio and the wide use of $3 \mathrm{D}$ printers.

Communication and Collaboration Problems. We observed that the number of methods for tactile graphics generation steadily increased from 2015 to 2020 and we expect more articles to be published in 2021. Meanwhile, we worried that many of the methods appeared to have been discontinued. To the best of our knowledge, the main reasons for these interruptions were the lack of funds allocated for projects, insufficient life experiments owing to COVID19 , or that the solutions provided by research centers and laboratories were not applicable in real life. In our opinion, the lack of general communication and cooperation between researchers and research centers is one of the obstacles to the development of this field. In this review, we have not observed collaborative projects between different countries or research centers, and they have not shared or transferred their solutions with others before papers were published. Overall, more than half of all the methods identified in the selected primary studies were dedicated to advancing educational systems for BVI individuals, in particular STEM subjects. Some of the identified systems were intended to create O\&M tactile maps.

Low-priced Technologies in Tactile Graphics Generation. It is also interesting to note that increasingly low-priced technologies $[11,21,35,54,55,59,62,66]$ were used to create automatic tactile graphics, which reduces the cost of AT and facilitates independent BVI individuals. Additionally, the development of $3 \mathrm{D}$ printers has led to the transition from $2 \mathrm{D}$ tactile 
graphics to 2.5D, and 3D tactile graphics are improving [62,65]. The reduced costs of electronic parts and devices make it possible to create refreshable braille displays and tactile pads for purchase $[7,54]$. In today's fast-paced world, people expect to have instant access to all information; however, tactile graphic creators need to be very careful about the quality of the information they produce.

The role of tactile graphics. After attempting to respond to RQ1, we can conclude that more than $80 \%$ of primary studies provided answers to RQ1. Different studies have suggested ideas and methods to improve the quality of education for BVI individuals and support their adaptation to the society in a variety of areas. To do this, they cooperated with O\&M instructors, TVI, librarians, engineers, and parents. They also used various methods and tools, such as 3D printers and models, tactile graphics with audio labels, QR codes, braille embossers, refreshable braille displays, smartphone features, text-to-speech and machine learning models. Almost two-thirds of the analyzed primary studies (18 papers) evaluated and experimented with BVI people to create technologies and methods. This is because tactile graphics, which seem easy and understandable to sighted people, can have complex shapes and incomprehensible lines to BVI individuals.

Currently Available Method, Software and Hardware. We addressed RQ2 by analyzing research articles and exploring commercially available technologies and software on the internet. We found a wide range of approaches from the research studies and real-life products. Admittedly, some research studies have not been put into practice but new ideas and results are commendable for their effectiveness. The refreshable Tactile Edu and Tactile Pro [31,72], with a special braille operating system, and other applications were developed based on scientific work. They are also available at low prices for BVI individuals. Other available tactile graphic technologies and applications, such as TactileView and ViewPlus, for BVI individuals have also been evolving for many years; however, their cost is still high for low- and middle-income users.

AI technologies in Tactile Graphics Generation. To answer RQ3, it was determined that AI technologies are still not widely used in the field of tactile graphics and AT for BVI individuals, and the question is not completely closed. Despite the fact that it took a long time for researchers in recent years, $\mathrm{AI}$ and machine learning solutions in this area are still scarce. Some web platforms that analyze the quality of web and personal images and classify whether an image is transformable to a tactile graphic as well as VR systems that present the shapes of objects have been developed using machine learning methods. In this context, a question arises: how will the current technological development in the AI era change the way traditional tactile graphics are created?

Currently Existing Gaps in Tactile Graphics Generation. We believe that this systematic review provided a brief overview of the current state of research in the field of automatic tactile graphics creation as well as new directions for development and research. The current gaps and issues we identified in the field of automatic tactile graphics generation during the review are listed below:

1. Despite the variety of tactile graphics generation methods and algorithms available, it is difficult to create simple tactile graphics from materials and images in STEM subjects.

2. Creating tactile graphics or $3 \mathrm{D}$ models requires a specialist and takes a long time to produce quality results because the full process is not automated.

3. Researchers working on this topic have not collaborated with BVI individuals. Thus, many science-based solutions have remained theoretical without reaching the production stage.

4. The cost of commercially available technologies and applications remains prohibitively expensive for low-income users.

5. Despite the development of AI algorithms for many years, methods for creating tactile graphics have mostly used traditional methods. Hence, it is crucial to create custom datasets to develop machine-learning models. 
6. Considering the increasing number of BVI people in the world, it is essential to expand the range of AT that assists them in receiving quality education.

We hope that researchers and developers will consider these gaps and issues to be one of the most important directions for them and find solutions.

\section{Conclusions}

Motivated by the lack of a systematic literature review on the status of research regarding automatic tactile graphics generation for BVI individuals, we conducted a review of 257 studies from 2015 to March 2021. Research papers were reviewed to provide insights into the dynamic nature of this study and provide possible directions for researchers and developers. We chose and reviewed 26 studies relevant to the objectives and questions of this research paper based on the rules of exclusion and inclusion. We analyzed the results from numerous digital libraries and electronic databases to provide a comprehensive data collection. As a result of the analysis, it was clear that image processing methods and audio information to create tactile graphics have been widely used in this area. Moreover, the use of 3D printers has led to the development of tactile graphics to a new level. The use of refreshable tactile displays and special software has advanced so far that they can display dynamic tactile graphics nearly in real time and improve the quality of the teaching process. All of the analyzed articles were available to researchers to review but some were not free. This is one way in which our analysis could be useful.

During the review, we answered several research questions. A survey of existing approaches could motivate researchers from all over the world to collaborate. In the systematic literature review, we also discovered current research gaps and revealed a significant requirement for new research contributions in this domain. We hope this will be a source of inspiration and encourage the tactile graphics generation and AT research community by highlighting opportunities for work in the future.

Author Contributions: M.M. designed the study and identified digital sources; M.M. and S.-Y.K. performed the primary studies screening and quality assessment; M.M. wrote the paper and S.-Y.K. made corrections to the text. Both authors have read and agreed to the published version of the manuscript.

Funding: This research received no external funding.

Acknowledgments: The authors would like to express my sincere gratitude and appreciation to Soon-Young Kim (Gachon University) for her support and quality assessment, comments, remarks, and engagement over the period in which this manuscript was written.

Conflicts of Interest: The authors declare no conflict of interest. 


\section{Appendix A}

\begin{tabular}{|c|c|c|c|c|}
\hline Article Technology & $\begin{array}{l}\text { Tactile Graphics in Education (E) and } \\
\text { Social Life (SL) }\end{array}$ & $\begin{array}{c}\text { Tactile Graphics Generation } \\
\text { Methodology }\end{array}$ & Experiments and Evaluation & Results and Conclusion \\
\hline $\begin{array}{c}{[38]} \\
\text { Tactile graphics }\end{array}$ & $\begin{array}{l}\text { Generating accessible text and tactile } \\
\text { graphics for a variety of graphics types } \\
\text { in an HTML document. (E) }\end{array}$ & $\begin{array}{l}\text { Machine learning models were developed } \\
\text { to classify graphics into categories. }\end{array}$ & $\mathrm{n} / \mathrm{a}$ & $\begin{array}{l}\text { The software generated tactile graphics for } \\
\text { diagrams, trees, graphs, flowcharts digital } \\
\text { circuits, bar chart, etc. }\end{array}$ \\
\hline $\begin{array}{l}{[48]} \\
\text { Tactile graphics }\end{array}$ & $\begin{array}{l}\text { Tactile graphics of seven bar charts, six } \\
\text { line charts, three pie charts, and five } \\
\text { scatterplots. (E) }\end{array}$ & $\begin{array}{l}\text { Tactile charts were developed with } \\
\text { different design characteristics to evaluate } \\
\text { their effectiveness. }\end{array}$ & $\begin{array}{l}48 \text { blind participants tested the chart types } \\
\text { and design features in reading data values. }\end{array}$ & $\begin{array}{l}13 \text { aspects were identified as essential in } \\
\text { remote studies with blind people. }\end{array}$ \\
\hline $\begin{array}{l}{[58]} \\
\text { Tactile graphics }\end{array}$ & $\begin{array}{c}\text { Generating tactile graphics from images } \\
\text { to perceive education materials and } \\
\text { environment. (SL) }\end{array}$ & $\begin{array}{c}\text { Salient objects were extracted and contours } \\
\text { were detected from images using Canny } \\
\text { edge detection. }\end{array}$ & $\begin{array}{l}\text { Quantitative and qualitative comparisons of } \\
\text { salient object detection algorithms were } \\
\text { evaluated. }\end{array}$ & $\begin{array}{c}\text { Visually salient objects were translated into } \\
\text { assistive technology systems for visually } \\
\text { impaired individuals. }\end{array}$ \\
\hline $\begin{array}{l}{[56]} \\
\text { Tactile graphics }\end{array}$ & $\begin{array}{l}\text { Tactile schematic symbols and nine } \\
\text { guidelines were proposed to create } \\
\text { readable tactile graphics. (E) }\end{array}$ & $\begin{array}{c}11 \text { rounds of iterations of six schematics } \\
\text { were completed to produce readable } \\
\text { versions. }\end{array}$ & $\begin{array}{l}\text { The schematics were evaluated by low-vision } \\
\text { and blind participants over the age of } 18 \text {. }\end{array}$ & $\begin{array}{l}\text { The schematic symbols of popular textbooks } \\
\text { and guidelines were produced. }\end{array}$ \\
\hline $\begin{array}{c}{[59]} \\
\text { Tactile graphics }\end{array}$ & $\begin{array}{l}\text { Detecting the outer boundaries and } \\
\text { inner edges of salient objects for simple } \\
\text { tactile graphics generation. (SL) }\end{array}$ & $\begin{array}{l}\text { The contours of the extracted salient } \\
\text { objects were printed as tactile graphics } \\
\text { using Index Braille Embosser. }\end{array}$ & $\begin{array}{l}14 \text { blind students evaluated the tactile } \\
\text { graphics and recognized the tactile graphics } \\
\text { content in one minute. }\end{array}$ & $\begin{array}{l}\text { The visually impaired students clearly } \\
\text { identified } 74 \% \text { of the tactile graphics. }\end{array}$ \\
\hline $\begin{array}{c}{[49]} \\
\text { Tactile graphics }\end{array}$ & $\begin{array}{l}\text { Software plugin for readily producing } \\
\text { variable-height tactile graphics of } \\
\text { biological molecules and proteins. (E) }\end{array}$ & $\begin{array}{l}\text { The plugin introduced representation } \\
\text { schemes designed to produce } \\
\text { variable-height tactile graphics. }\end{array}$ & $\begin{array}{l}\text { Three-dimensional printed models and } \\
\text { tactile graphics enabled blind students to } \\
\text { analyze the protein structures. }\end{array}$ & $\begin{array}{l}\text { The results enabled undergraduate blind } \\
\text { students to conduct quality research on } \\
\text { protein structure. }\end{array}$ \\
\hline $\begin{array}{c}{[50]} \\
\text { Tactile graphics }\end{array}$ & $\begin{array}{l}\text { A controlled user study of four tactile } \\
\text { representations of social networks and } \\
\text { biological networks. (E) }\end{array}$ & $\begin{array}{l}\text { Four tactile representations of network } \\
\text { data were generated using different } \\
\text { methods and swell paper. }\end{array}$ & $\begin{array}{l}\text { Eight participants reported about the } \\
\text { overview, connectivity cluster, and common } \\
\text { connection of the network data. }\end{array}$ & $\begin{array}{c}\text { All the participants noticed that the two } \\
\text { node-link diagram representations were } \\
\text { more natural and intuitive. }\end{array}$ \\
\hline $\begin{array}{l}{[54]} \\
\text { Tactile graphics }\end{array}$ & $\begin{array}{l}\text { Automatically translating characters and } \\
\text { images into tactile graphics for an } \\
\text { electronic braille page. (E) }\end{array}$ & $\begin{array}{l}\text { The labeling and filtering of a scanned } \\
\text { image, character, and graphic labels were } \\
\text { determined. }\end{array}$ & $\begin{array}{c}10 \text { visually impaired individuals evaluated } \\
\text { the electronic braille pages printed by the } \\
\text { braille printer. }\end{array}$ & $\begin{array}{l}\text { Time and cost were significantly reduced and } \\
\text { more reading materials were provided for } \\
\text { the visually impaired individuals. }\end{array}$ \\
\hline $\begin{array}{c}{[55]} \\
\text { Tactile graphics }\end{array}$ & $\begin{array}{l}\text { Automatically converting scanned } \\
\text { textbook images to tactile diagrams and } \\
\text { text into braille. (E) }\end{array}$ & $\begin{array}{l}\text { This includes the extraction and } \\
\text { recognition of text and geometric lines and } \\
\text { circles. }\end{array}$ & $\mathrm{n} / \mathrm{a}$ & $\begin{array}{c}\text { The first version of the software was capable } \\
\text { of enhancing the productivity of tactile } \\
\text { designers. }\end{array}$ \\
\hline $\begin{array}{l}{[51]} \\
\text { Tactile graphics with audio }\end{array}$ & $\begin{array}{l}\text { Improving the tactile chart creation } \\
\text { process by an automation tool that } \\
\text { includes an accessible GUI. (E) }\end{array}$ & $\begin{array}{l}\text { The production process was divided into } \\
\text { five basic components such as Input Data, } \\
\text { User Input, etc. }\end{array}$ & $\begin{array}{l}\text { Two blind participants evaluated the bar and } \\
\text { line charts and scatterplots in two-hour } \\
\text { sessions. }\end{array}$ & $\begin{array}{c}\text { The structure and elements of the charts and } \\
\text { all properties were recognized by both } \\
\text { participants. }\end{array}$ \\
\hline $\begin{array}{l}{[11]} \\
\text { Tactile graphics with audio }\end{array}$ & $\begin{array}{c}\text { Tracking a student's fingers by a } \\
\text { machine vision-based tactile graphics } \\
\text { helper (TGH). (E) }\end{array}$ & $\begin{array}{l}\text { The TGH includes a mounted camera } \\
\text { placed across the tactile graphic and } \\
\text { recognizes different tactile graphics. }\end{array}$ & $\begin{array}{l}\text { Three participants who were university } \\
\text { students with STEM majors tested the TGH } \\
\text { with six tactile graphics. }\end{array}$ & $\begin{array}{c}\text { The TGH can improve STEM students' skills } \\
\text { and efficiency in accessing educational } \\
\text { content. }\end{array}$ \\
\hline
\end{tabular}




\begin{tabular}{|c|c|c|c|c|}
\hline Article Technology & $\begin{array}{l}\text { Tactile Graphics in Education (E) and } \\
\text { Social Life (SL) }\end{array}$ & $\begin{array}{c}\text { Tactile Graphics Generation } \\
\text { Methodology }\end{array}$ & Experiments and Evaluation & Results and Conclusion \\
\hline $\begin{array}{l}{[52]} \\
\text { Tactile graphics with audio }\end{array}$ & $\begin{array}{c}\text { A device that provides audio and haptic } \\
\text { guidance via skin-stretch feedback to a } \\
\text { user's hand. (E) }\end{array}$ & $\begin{array}{l}\text { The device can support two teaching } \\
\text { scenarios and two guidance interactions. }\end{array}$ & $\begin{array}{l}\text { One blind engineering student evaluated } \\
\text { two developed applications that focused on } \\
\text { the learning scenario. }\end{array}$ & $\begin{array}{l}\text { All the participants and experts of tactile } \\
\text { graphics commented for improving several } \\
\text { technical functions. }\end{array}$ \\
\hline $\begin{array}{l}{[21]} \\
\text { Tactile graphics with audio }\end{array}$ & $\begin{array}{l}\text { Tactile graphics with a voice (TGV), a } \\
\text { device used to access label information } \\
\text { in tactile graphics using } \mathrm{QR} \text { codes to } \\
\text { replace the text. (E) }\end{array}$ & $\begin{array}{l}\text { TGV comprises tactile graphics with } \mathrm{QR} \\
\text { code labels and a smartphone application. }\end{array}$ & $\begin{array}{l}10 \text { blind participants tested the tasks using } \\
\text { three modes on the smartphone application } \\
\text { (1) no guidance, (2) verbal, (3) } \\
\text { finger-pointing guidance. }\end{array}$ & $\begin{array}{c}\text { The accuracy of the } 12 \text { tasks did not vary } \\
\text { across the different modes (silent mode: } 88 \% \text {; } \\
\text { verbal mode: } 88 \% \text {; finger Pointing mode: } \\
89 \% \text { ). }\end{array}$ \\
\hline $\begin{array}{l}{[53]} \\
\text { Tactile graphics with audio }\end{array}$ & $\begin{array}{l}\text { A platform that shares graphic math } \\
\text { content (charts, geometric figures, etc.) } \\
\text { in audio-tactile form for the blind. (E) }\end{array}$ & $\begin{array}{c}\text { The test bench consists of a touch tablet } \\
\text { and developed software for interactive } \\
\text { audio-tactile display. }\end{array}$ & $\begin{array}{l}10 \text { blind students solved } 15 \text { math exercises } \\
\text { containing graphic content available in } \\
\text { tactile form. }\end{array}$ & $\begin{array}{l}\text { The developed method can be helpful for } \\
\text { both a teacher and a blind student for } \\
\text { self-study. }\end{array}$ \\
\hline $\begin{array}{l}{[61]} \\
\text { Tactile graphics with audio }\end{array}$ & $\begin{array}{l}\text { An audio-tactile graphic system outputs } \\
\text { an audio guidance from iPhone. (SL) }\end{array}$ & $\begin{array}{l}\text { The system uses edge detection from the } \\
\text { RGB image and extracts coordinates of the } \\
\text { pixels. }\end{array}$ & $\begin{array}{l}\text { Eight blind participants tested the system in } \\
\text { three sessions using the tactile maps with six, } \\
12 \text {, and } 30 \text { rooms. }\end{array}$ & $\begin{array}{l}\text { Audio guidance function is effective for } \\
\text { understanding tactile graphics. }\end{array}$ \\
\hline $\begin{array}{c}{[65]} \\
3 D \text { tactile graphics }\end{array}$ & $\begin{array}{l}\text { Illustration design of 3D objects assumes } \\
\text { the identification of relevant data in } \\
\text { topology and geometry. (SL) }\end{array}$ & $\begin{array}{l}\text { Multi-projection rendering strategy was } \\
\text { introduced to display the geometric } \\
\text { information of 3D geometry. }\end{array}$ & $\begin{array}{l}20 \text { blind participants tested the 3D object } \\
\text { replication and tactile illustrations of teapot, } \\
\text { lamp, eyeglasses, chair, etc. }\end{array}$ & $\begin{array}{l}\text { The results can be used as a tool to depict } \\
\text { products ranging from furniture to art pieces } \\
\text { in a museum. }\end{array}$ \\
\hline $\begin{array}{c}{[62]} \\
3 D \text { tactile graphics }\end{array}$ & $\begin{array}{l}\text { 3D printed maps on-site at a public } \\
\text { event to examine their suitability for the } \\
\text { design of future 3D maps. (SL) }\end{array}$ & $\begin{array}{l}\text { All the 3D maps were designed by a } \\
\text { researcher with } 20 \text { years of experience in } \\
\text { tactile graphics. }\end{array}$ & $\begin{array}{l}10 \text { participants tested the 3D maps and } \\
\text { answered different questions to evaluate the } \\
\text { usefulness of these maps. }\end{array}$ & $\begin{array}{l}\text { Different recommendations were proposed } \\
\text { for the design and use of 3D printed maps } \\
\text { for accessibility. }\end{array}$ \\
\hline $\begin{array}{c}{[60]} \\
3 D \text { tactile graphics }\end{array}$ & $\begin{array}{l}\text { Six stakeholder groups attempt to create } \\
\text { 3D printable accessible tactile pictures } \\
\text { (3DP-ATPs). (SL) }\end{array}$ & $\begin{array}{c}\text { Libraries, schools, volunteer centers, art } \\
\text { galleries to offer workshops on 3DP-ATPs } \\
\text { at their sites. }\end{array}$ & $\begin{array}{l}69 \text { participants focused on creating 3D } \\
\text { printable 3DP-ATPs and reported their } \\
\text { different experiences. }\end{array}$ & $\begin{array}{l}\text { The participants offered advice for making } \\
\text { the design task: five different skillsets. }\end{array}$ \\
\hline
\end{tabular}




\begin{tabular}{|c|c|c|c|c|}
\hline Article Technology & $\begin{array}{l}\text { Tactile Graphics in Education (E) and } \\
\text { Social Life (SL) }\end{array}$ & $\begin{array}{c}\text { Tactile Graphics Generation } \\
\text { Methodology }\end{array}$ & Experiments and Evaluation & Results and Conclusion \\
\hline $\begin{array}{c}{[31]} \\
\text { Refreshabletactile displays }\end{array}$ & $\begin{array}{l}\text { Two methodologies are presented for } \\
\text { delivering multimedia content to BVI } \\
\text { individuals using a haptic and braille } \\
\text { display. (SL) }\end{array}$ & $\begin{array}{c}\text { A braille electronic book reader application } \\
\text { that can share text, figures, and audio } \\
\text { content. }\end{array}$ & $\begin{array}{l}\text { The experiment was performed by using a } \\
\text { combination of tablet and smartphone. }\end{array}$ & $\begin{array}{l}\text { Braille display increases the accessibility of } \\
\text { BVI individuals to multimedia as well as 3D } \\
\text { and 2D haptic information delivery. }\end{array}$ \\
\hline $\begin{array}{l}{[66]} \\
\text { Refreshabletactile displays }\end{array}$ & $\begin{array}{l}\text { The transformation of DAISY and EPUB } \\
\text { formats into } 2 \mathrm{D} \text { braille display. (SL) }\end{array}$ & $\begin{array}{l}\text { This application was based on DAISY and } \\
\text { EPUB. It supports contents display, text } \\
\text { highlight, MP3, TTS. }\end{array}$ & $\begin{array}{l}\text { The tablets and smartphones used were } \\
\text { Samsung Tab S, Galaxy Tab S2 8.0, Samsung } \\
\text { S7 Edge, S6, and Note 5. }\end{array}$ & $\begin{array}{l}\text { The 2D mobile braille displaycan be very } \\
\text { useful for literature, scientific figures, and } \\
\text { education. }\end{array}$ \\
\hline $\begin{array}{l}{[36]} \\
\text { Tactile graphics with AI }\end{array}$ & $\begin{array}{l}\text { A machine learning (ML) model that } \\
\text { identifies suitable and unsuitable images } \\
\text { for tactile graphics (TG). (SL) }\end{array}$ & $\begin{array}{l}\text { The ML model was built on top of } \\
\text { MobileNet, and it classifies images into } \\
\text { two categories. }\end{array}$ & $\begin{array}{l}\text { The identification, search, and retraining } \\
\text { functionalities were implemented in a web } \\
\text { platform. }\end{array}$ & $\begin{array}{c}\text { A web platform consists of (1) images that } \\
\text { are transformable to TGs and (2) an online } \\
\text { learning model. }\end{array}$ \\
\hline $\begin{array}{l}{[57]} \\
\text { Tactile graphics with AI }\end{array}$ & $\begin{array}{l}\text { Tactile educational tools for presenting } \\
\text { the shapes of objects to visually impaired } \\
\text { students using VR. (E) }\end{array}$ & $\begin{array}{l}\text { 3D-CAD data were used to express the } \\
\text { shapes of objects. A haptic device was } \\
\text { used to develop a system. }\end{array}$ & $\begin{array}{l}\text { Two blind and five low-vision persons } \\
\text { guessed the shape of the objects. }\end{array}$ & $\begin{array}{l}\text { The participants seemed to have difficulty in } \\
\text { identifying the shape because of the reduced } \\
\text { amount of information. }\end{array}$ \\
\hline
\end{tabular}




\section{References}

1. Luo, S.; Bimbo, J.; Dahiya, R.; Liu, H. Robotic tactile perception of object properties: A review. Mechatronics 2017, 48, 54-67. [CrossRef]

2. Brulé, E.; Tomlinson, B.J.; Metatla, O.; Jouffrais, C.; Serrano, M. Review of Quantitative Empirical Evaluations of Technology for People with Visual Impairments. In Proceedings of the 2020 CHI Conference on Human Factors in Computing Systems, Honolulu, HI, USA, 25-30 April 2020; pp. 1-14.

3. Matthew, B.; Holloway, L.; Reinders, S.; Goncu, C.; Marriott, K. Technology Developments in Touch-Based Accessible Graphics: A Systematic Review of Research 2010-2020. In Proceedings of the 2021 CHI Conference on Human Factors in Computing Systems, Yokohama, Japan, 8-13 May 2021; pp. 1-15.

4. Wabiński, J.; Mościcka, A. Automatic (Tactile) Map Generation-A Systematic Literature Review. ISPRS Int. J. Geo-Inf. 2019, 8 , 293. [CrossRef]

5. World Health Organization. World Report on Vision; World Health Organization: Geneva, Switzerland, 2019; Licence: CC BY-NC-SA 3.0 IGO; Available online: https:/ / www.who.int/publications/i/item/9789241516570 (accessed on 4 March 2021).

6. Zebehazy, K.T.; Wilton, A.P. Quality, importance, and instruction: The perspectives of teachers of students with visual impairments on graphics use by students. J. Vis. Impair. Blind. 2014, 108, 5-16. [CrossRef]

7. Melfi, G.; Müller, K.; Schwarz, T.; Jaworek, G.; Stiefelhagen, R. Understanding what you feel: A mobile audio-tactile system for graphics used at schools with students with visual impairment. In Proceedings of the $2020 \mathrm{CHI}$ Conference on Human Factors in Computing Systems, Honolulu, HI, USA, 25-30 April 2020; pp. 1-12.

8. Ferro, T.J.; Pawluk, D.T. Automatic image conversion to tactile graphic. In Proceedings of the 15th International ACM SIGACCESS Conference on Computers and Accessibility (ASSETS '13), Bellevue, WA, USA, 21-23 October 2013; pp. 1-2.

9. Zebehazy, K.T.; Wilton, A.P. Straight from the source: Perceptions of students with visual impairments about graphic use. J. Vis. Impair. Blind. 2014, 108, 275-286. [CrossRef]

10. Smith, D.W.; Smothers, S.M. The role and characteristics of tactile graphics in secondary mathematics and science textbooks in braille. J. Vis. Impair. Blind. 2012, 106, 543-554. [CrossRef]

11. Fusco, G.; Morash, V.S. The tactile graphics helper: Providing audio clarification for tactile graphics using machine vision. In Proceedings of the 17th International ACM SIGACCESS Conference on Computers \& Accessibility, Lisbon, Portugal, 26-28 October 2015; pp. 97-106.

12. Ferro, T.J.; Pawluk, D.T. Providing Dynamic Access to Electronic Tactile Diagrams. In Proceedings of the International Conference on Universal Access in Human-Computer Interaction, Las Vegas, NV, USA, 15-20 July 2017; Springer: Cham, Switzerland, 2017; pp. 269-282.

13. Way, T.P.; Barner, K.E. Automatic visual to tactile translation-Part I: Human factors, access methods, and image manipulation. IEEE Trans. Rehabil. Eng. 1997, 5, 81-94. [CrossRef]

14. Way, T.P.; Barner, K.E. Automatic visual to tactile translation-Part II: Evaluation of the TACTile Image Creation System. IEEE Trans. Rehabil. Eng. 1997, 5, 95-105. [CrossRef]

15. Krufka, S.E.; Barner, K.E.; Aysal, T.C. Visual to tactile conversion of vector graphics. IEEE Trans. Neural Syst. Rehabil. Eng. 2007, 15, 310-321. [CrossRef]

16. Jayant, C.; Renzelmann, M.; Wen, D.; Krisnandi, S.; Ladner, R.; Comden, D. Automated Tactile Graphics Translation: In the Field. In Proceedings of the 9th International ACM SIGACCESS Conference on Computers and Accessibility, Tempe, AZ, USA, 15-17 October 2007; pp. 75-82.

17. Hernandez, S.E.; Barner, K.E. Joint Region Merging Criteria for Watershed-Based Image Segmentaion. In Proceedings of the International Conference on Image Processing, Vancouver, BC, Canada, 10-13 September 2000; Volume 2, pp. $108-111$.

18. Ladner, R.E.; Ivory, M.Y.; Rao, R.; Burgstahler, S.; Comden, D.; Hahn, S.; Renzelmann, M.J.; Krisnandi, S.; Ramasamy, M.; Slabosky, B.; et al. Automating tactile graphics translation. In Proceedings of the 7th International ACM SIGACCESS Conference on Computers and Accessibility, Baltimore, MD, USA, 9-12 October 2005; pp. 150-157.

19. Brock, A.M.; Truillet, P.; Oriola, B.; Picard, D.; Jouffrais, C. Interactivity improves usability of geographic maps for visually impaired people. Hum. Comput. Interact. 2015, 30, 156-194. [CrossRef]

20. Suzuki, R.; Stangl, A.; Gross, M.D.; Yeh, T. FluxMarker: Enhancing Tactile Graphics with Dynamic Tactile Markers. In Proceedings of the 19th International ACM SIGACCESS Conference on Computers and Accessibility, Baltimore, MD, USA, 29 October-1 November 2017; pp. 190-199.

21. Baker, C.M.; Milne, L.R.; Scofield, J.; Bennett, C.L.; Ladner, R.E. Tactile graphics with a voice: Using QR codes to access text in tactile graphics. In Proceedings of the 16th International ACM SIGACCESS Conference on Computers \& Accessibility, New York, NY, USA, 20-22 October 2014; pp. 75-82.

22. Miele, J.A.; Landau, S.; Gilden, D. Talking TMAP: Automated generation of audio-tactile maps using Smith-Kettlewell's TMAP software. Br. J. Vis. Impair. 2006, 24, 93-100. [CrossRef]

23. Yu, W.; Ramloll, R.; Brewster, S. Haptic graphs for blind computer users. In Proceedings of the International Workshop on Haptic Human-Computer Interaction, Glasgow, UK, 31 August-1 September 2000; Springer: Berlin/Heidelberg, Germany, 2000; pp. $41-51$.

24. Rice, M.; Jacobson, R.D.; Golledge, R.G.; Jones, D. Design considerations for haptic and auditory map interfaces. Cartogr. Geogr. Inf. Sci. 2005, 32, 381-391. [CrossRef] 
25. Zeng, L.; Weber, G. Audio-haptic browser for a geographical information system. In Proceedings of the International Conference on Computers for Handicapped Persons, Vienna, Austria, 14-16 July 2010; Springer: Berlin, Germany, 2010 ; pp. 466-473.

26. McGookin, D.; Robertson, E.; Brewster, S. Clutching at straws: Using tangible interaction to provide non-visual access to graphs. In Proceedings of the SIGCHI conference on human factors in computing systems, Atlanta, GA, USA, 10-15 April 2010; pp. $1715-1724$.

27. Ramloll, R.; Yu, W.; Brewster, S.; Riedel, B.; Burton, M.; Dimigen, G. Constructing sonified haptic line graphs for the blind student: First steps. In Proceedings of the Fourth International ACM Conference on Assistive Technologies, Arlington, VA, USA, 13-15 November 2000; pp. 17-25.

28. Brown, C.; Hurst, A. Viztouch: Automatically generated tactile visualizations of coordinate spaces. In Proceedings of the Sixth International Conference on Tangible, Embedded and Embodied Interaction, Kingston, ON, Canada, 19-22 February 2012; pp. 131-138.

29. Štampach, R.; Mulícková, E. Automated generation of tactile maps. J. Maps 2016, 12, 532-540. [CrossRef]

30. Jungil, J.; Hongchan, Y.; Hyelim, L.; Jinsoo, C. Graphic haptic electronic board-based education assistive technology system for blind people. In Proceedings of the 2015 IEEE International Conference on Consumer Electronics (ICCE), Las Vegas, NV, USA, 9-12 January 2015; pp. 364-365.

31. Kim, S.; Ryu, Y.; Cho, J.; Ryu, E.-S. Towards Tangible Vision for the Visually Impaired through 2D Multiarray Braille Display. Sensors 2019, 19, 5319. [CrossRef] [PubMed]

32. Prescher, D.; Weber, G.; Spindler, M. A tactile windowing system for blind users. In Proceedings of the 12th International ACM SIGACCESS conference on Computers and accessibility, Orlando, FL, USA, 25-27 October 2010; pp. 91-98.

33. Schmitz, B.; Ertl, T. Interactively displaying maps on a tactile graphics display. In Proceedings of the 2012 Workshop on Spatial Knowledge Acquisition with Limited Information Displays, Bavaria, Germany, 31 August 2012; pp. 13-18.

34. Zeng, L.; Weber, G. ATMap: Annotated tactile maps for the visually impaired. In Cognitive Behavioural Systems; Lecture Notes in Computer Science; Springer: Berlin, Germany, 2012; Volume 7403, pp. 290-298.

35. Felipe, M.P.; Guerra-Gómez, J.A. ML to Categorize and Find Tactile Graphics. Bachelor's Thesis, Universidad de los Andes, Bogota, Columbia, 2020.

36. Gonzalez, R.; Gonzalez, C.; Guerra-Gomez, J.A. Tactiled: Towards more and better tactile graphics using machine learning. In Proceedings of the 21st International ACM SIGACCESS Conference on Computers and Accessibility, Pittsburgh, PA, USA, 28-30 October 2019; pp. 530-532.

37. Guinness, D.; Muehlbradt, A.; Szafir, D.; Kane, S.K. RoboGraphics: Dynamic Tactile Graphics Powered by Mobile Robots. In Proceedings of the 21st International ACM SIGACCESS Conference on Computers and Accessibility, Pittsburgh, PA, USA, 28-30 October 2019; pp. 318-328.

38. Bose, R.; Bauer, M.A.; Jürgensen, H. Utilizing Machine Learning Models for Developing a Comprehensive Accessibility System for Visually Impaired People. In Proceedings of the International Conference on Computers Helping People with Special Needs, Lecco, Italy, 9-11 September 2020; p. 83.

39. Yuksel, B.F.; Fazli, P.; Mathur, U.; Bisht, V.; Kim, S.J.; Lee, J.J.; Jin, S.J.; Siu, Y.-T.; Miele, J.A.; Yoon, I. Human-in-the-Loop Machine Learning to Increase Video Accessibility for Visually Impaired and Blind Users. In Proceedings of the 2020 ACM Designing Interactive Systems Conference, New York, NY, USA, 6-10 July 2020; pp. 47-60.

40. Yuksel, B.F.; Kim, S.J.; Jin, S.J.; Lee, J.J.; Fazli, P.; Mathur, U.; Bisht, V.; Yoon, I.; Siu, Y.-T.; Miele, J.A. Increasing Video Accessibility for Visually Impaired Users with Human-in-the-Loop Machine Learning. In Proceedings of the Extended Abstracts of the 2020 CHI Conference on Human Factors in Computing Systems, Honolulu, HI, USA, 25-30 April 2020; pp. 1-9.

41. Buonamici, F.; Carfagni, M.; Furferi, R.; Governi, L.; Volpe, Y. Are we ready to build a system for assisting blind people in tactile exploration of bas-reliefs? Sensors 2016, 16, 1361. [CrossRef] [PubMed]

42. Lin, Y.; Wang, K.; Yi, W.; Lian, S. Deep learning based wearable assistive system for visually impaired people. In Proceedings of the IEEE/CVF International Conference on Computer Vision Workshops, Seoul, Korea, 27-28 October 2019.

43. Klingenberg, O.G.; Holkesvik, A.H.; Augestad, L.B.; Erdem, E. Research evidence for mathematics education for students with visual impairment: A systematic review. Cogent Educ. 2019, 6, 1626322. [CrossRef]

44. Oh, U.; Joh, H.; Lee, Y.J. Image Accessibility for Screen Reader Users: A Systematic Review and a Road Map. Electronics 2021, 10, 953. [CrossRef]

45. Cole, H. Tactile cartography in the digital age: A review and research agenda. Prog. Hum. Geogr. 2021, 45, 834-854.

46. Kitchenham, B.A.; Charters, S. Guidelines for Performing Systematic Literature Reviews in Software Engineering Version 2.3; ACM Press: New York, NY, USA, 2007.

47. Page, M.J.; Moher, D.; Bossuyt, P.M.; Boutron, I.; Hoffmann, T.C.; Mulrow, C.D.; Shamseer, L.; Tetzlaff, J.M.; Akl, E.A.; Brennan, S.E.; et al. PRISMA 2020 explanation and elaboration: Updated guidance and exemplars for reporting systematic reviews. Br. Med. J. 2021, 372. [CrossRef]

48. Engel, C.; Weber, G. User study: A detailed view on the effectiveness and design of tactile charts. In Proceedings of the IFIP Conference on Human-Computer Interaction, Paphos, Cyprus, 2-6 September 2019; Springer: Cham, Switzerland, 2019 ; pp. 63-82.

49. Show, O.R.; Hadden-Perilla, J.A. TactViz: A VMD Plugin for Tactile Visualization of Protein Structures. J. Sci. Educ. Stud. Disabil. 2020, 23, 14 . 
50. Yang, Y.; Marriott, K.; Butler, M.; Goncu, C.; Holloway, L. Tactile presentation of network data: Text, matrix or diagram? In Proceedings of the Extended Abstracts of the 2020 CHI Conference on Human Factors in Computing Systems, Honolulu, HI, USA, 25-30 April 2020; pp. 1-12.

51. Engel, C.; Müller, E.F.; Weber, G. SVGPlott: An accessible tool to generate highly adaptable, accessible audio-tactile charts for and from blind and visually impaired people. In Proceedings of the 12th ACM International Conference on PErvasive Technologies Related to Assistive Environments, Rhodes, Greece, 5-7 June 2019; pp. 186-195.

52. Chase, E.D.; Siu, A.F.; Boadi-Agyemang, A.; Kim, G.S.; Gonzalez, E.J.; Follmer, S. PantoGuide: A Haptic and Audio Guidance System to Support Tactile Graphics Exploration. In Proceedings of the 22nd International ACM SIGACCESS Conference on Computers and Accessibility, Virtual Event, Greece, 26-28 October 2020; pp. 1-4.

53. Maćkowski, M.; Brzoza, P.; Meisel, R.; Bas, M.; Spinczyk, D. Platform for Math Learning with Audio-Tactile Graphics for Visually Impaired Students. In Proceedings of the International Conference on Computers Helping People with Special Needs, Lecco, Italy, 9-11 September 2020; p. 75.

54. Park, T.; Jung, J.; Cho, J. A method for automatically translating print books into electronic Braille books. Sci. China Inf. Sci. 2016, 59, 1-14. [CrossRef]

55. Gupta, R.; Balakrishnan, M.; Rao, P.V.M. Tactile diagrams for the visually impaired. IEEE Potentials 2017, 36, 14-18. [CrossRef]

56. Race, L.; Fleet, C.; Miele, J.A.; Igoe, T.; Hurst, A. Designing Tactile Schematics: Improving Electronic Circuit Accessibility. In Proceedings of the 21st International ACM SIGACCESS Conference on Computers and Accessibility, Pittsburgh, PA, USA, 28-30 October 2019; pp. 581-583.

57. Asakawa, N.; Wada, H.; Shimomura, Y.; Takasugi, K. Development of VR Tactile Educational Tool for Visually Impaired Children: Adaptation of Optical Motion Capture as a Tracker. Sens. Mater. 2020, 32, 3617-3626.

58. Yoon, H.; Kim, B.-H.; Mukhiddinov, M.; Cho, J. Salient Region Extraction based on Global Contrast Enhancement and Saliency Cut for Image Information Recognition of the Visually Impaired. KSII Trans. Internet Inf. Syst. 2018, 12, $2287-2312$.

59. Abdusalomov, A.; Mukhiddinov, M.; Djuraev, O.; Khamdamov, U.; Whangbo, T.K. Automatic salient object extraction based on locally adaptive thresholding to generate tactile graphics. Appl. Sci. 2020, 10, 3350. [CrossRef]

60. Stangl, A.; Hsu, C.-L.; Yeh, T. Transcribing across the senses: Community efforts to create 3D printable accessible tactile pictures for young children with visual impairments. In Proceedings of the 17th International ACM SIGACCESS Conference on Computers \& Accessibility, Lisbon, Portugal, 26-28 October 2015; pp. 127-137.

61. Hashimoto, Y.; Takagi, N. Development of audio-tactile graphic system aimed at facilitating access to visual information for blind people. In Proceedings of the 2018 IEEE International Conference on Systems, Man, and Cybernetics (SMC), Miyazaki, Japan, 7-10 October 2018; pp. 2283-2288.

62. Holloway, L.; Marriott, K.; Butler, M.; Reinders, S. 3D Printed Maps and Icons for Inclusion: Testing in the Wild by People who are Blind or have Low Vision. In Proceedings of the 21st International ACM SIGACCESS Conference on Computers and Accessibility, Pittsburgh, PA, USA, 28-30 October 2019; pp. 183-195.

63. Thevin, L.; Brock, A.M. Augmented reality for people with visual impairments: Designing and creating audio-tactile content from existing objects. In Proceedings of the International Conference on Computers Helping People with Special Needs, Linz, Austria, 11-13 July 2018; Springer: Cham, Switzerland, 2018; pp. 193-200.

64. Cavazos, Q.L.; Bartolomé, J.I.; Cho, J. Accessible Visual Artworks for Blind and Visually Impaired People: Comparing a Multimodal Approach with Tactile Graphics. Electronics. 2021, 10, 297. [CrossRef]

65. Panotopoulou, A.; Zhang, X.; Qiu, T.; Yang, X.-D.; Whiting, E. Tactile line drawings for improved shape understanding in blind and visually impaired users. ACM Trans. Graph. 2020, 39, 89. [CrossRef]

66. Kim, S.; Park, E.-S.; Ryu, E.-S. Multimedia vision for the visually impaired through 2D multiarray braille display. Appl. Sci. 2019, 9, 878. [CrossRef]

67. Thinkable, Tactile Drawing Software. Available online: https://thinkable.nl/ (accessed on 4 March 2021).

68. American Printing House, Tactile Graphics Kit. Available online: https://www.aph.org/product/tactile-graphics-kit/ (accessed on 4 March 2021).

69. American Thermoform, Tactile Graphics. Available online: http://www.americanthermoform.com/product-category/tactilegraphics / (accessed on 5 March 2021).

70. ViewPlus, IVEO 3 Hands-On Learning System. Available online: https:/ /viewplus.com/product/iveo-3-hands-on-learningsystem/ (accessed on 4 March 2021).

71. SeeWriteHear, Braille \& Tactile Graphics. Available online: https://www.seewritehear.com/services/document-accessibility/ braille-tactile-graphics / (accessed on 5 March 2021).

72. Power Contents Technology, Tactile Pro \& Edu. Available online: http:/ / www.powerct.kr/ (accessed on 5 March 2021).

73. Orbit Research, Graphiti. Available online: http://www.orbitresearch.com/product/graphiti/ (accessed on 4 March 2021).

74. Bristol Braille Technology, Canute 360. Available online: http://www.bristolbraille.co.uk/index.htm (accessed on 5 March 2021).

75. González Álvarez, C.E. ML to Categorize and Translate Images into Tactile Graphics. Bachelor's Thesis, Universidad de los Andes, Bogota, Columbia, 2020. 